\title{
UNCERTAINTY SHOCKS AND BUSINESS CYCLE RESEARCH
}

Jesús Fernández-Villaverde

Pablo A. Guerrón-Quintana

Working Paper 26768

http://www.nber.org/papers/w26768

\author{
NATIONAL BUREAU OF ECONOMIC RESEARCH \\ 1050 Massachusetts Avenue \\ Cambridge, MA 02138 \\ February 2020
}

Ryan Zalla provided most timely research assistance. We thank Ryo Jinnai for extensive discussions and feedback on models with financial frictions. The views expressed herein are those of the authors and do not necessarily reflect the views of the National Bureau of Economic Research.

NBER working papers are circulated for discussion and comment purposes. They have not been peer-reviewed or been subject to the review by the NBER Board of Directors that accompanies official NBER publications.

(C) 2020 by Jesús Fernández-Villaverde and Pablo A. Guerrón-Quintana. All rights reserved. Short sections of text, not to exceed two paragraphs, may be quoted without explicit permission provided that full credit, including $(\odot)$ notice, is given to the source. 
Uncertainty Shocks and Business Cycle Research

Jesús Fernández-Villaverde and Pablo A. Guerrón-Quintana

NBER Working Paper No. 26768

February 2020

JEL No. E30,E32,E50

\begin{abstract}
$\underline{\text { ABSTRACT }}$
We review the literature on uncertainty shocks and business cycle research. First, we motivate the study of uncertainty shocks by documenting the presence of time-variation in the volatility of macroeconomic time series. Second, we enumerate the mechanisms that researchers have postulated to link uncertainty shocks and business cycles. Third, we outline how we can specify uncertainty shocks. Fourth, we postulate a real business cycle model augmented with financial frictions and uncertainty shocks. Fifth, we use the model to illustrate our previous discussions and to show how uncertainty shocks can be expansionary.
\end{abstract}

Jesús Fernández-Villaverde

Department of Economics

University of Pennsylvania

The Ronald O. Perelman Center

for Political Science and Economics

133 South 36th Street Suite 150

Philadelphia, PA 19104

and CEPR

and also NBER

jesusfv@econ.upenn.edu

Pablo A. Guerrón-Quintana

Boston College

Department of Economics

140 Commonwealth Avenue

Malloney Hall 325

Chestnut Hill, MA 02467

pguerron@gmail.com 


\section{Introduction}

During the last decade, a vibrant literature has explored the role of uncertainty and its time-variation in driving business cycles. ${ }^{1}$ From the empirical side, Bloom et al. (2016) have demonstrated that simple indices of uncertainty measured from newspaper articles, the number of federal tax code provisions set to expire in future years, and forecasters' disagreements clearly correlate with economic activity. In particular, macro uncertainty seems to be countercyclical: times of high uncertainty are times of low economic activity (at this moment, this statement does not imply any causal direction). Dozens of papers have asserted the robustness of this basic finding along with a multitude of modifications of the research design, econometric approaches, and datasets.

From a theoretical perspective, the work by Bloom (2009), Fernández-Villaverde et al. (2011), Fernández-Villaverde et al. (2015a), and Justiniano and Primiceri (2008) has presented equilibrium models where "uncertainty shocks," i.e., increases in the standard deviation of the shocks that hit the economy, can account for a significant share of aggregate fluctuations. These papers move beyond Bloom et al. (2016) and assert causality: uncertainty shocks drive part of the business cycle. An extensive literature has followed these pioneering studies and extended the theoretical models in many directions.

This paper reviews this literature on uncertainty shocks and business cycle research. In the interest of space, we will focus on equilibrium models of the business cycle with a representative agent in the tradition of most of the papers in Cooley (1995). To display many of the ideas, we will postulate, solve, and calibrate a real business cycle model with financial frictions.

This model will be rich enough to incorporate most of the mechanisms outlined in the literature linking uncertainty shocks with business cycles and, yet, simple enough to be understood quickly. For example, we will not add nominal rigidities or extra layers of real rigidities. And, instead of a multitude of shocks, we will have only six shocks -three level and three uncertainty shocks- joined in pairs of one level and one uncertainty shock. The first pair will work as demand shocks. The second pair will work as supply shocks. The third and final pair will work as financial friction shocks. The trinity of demand, supply, and financial shocks will capture the intuition often used by researchers to organize their thinking about business cycles and be easy enough to separate from each other.

\footnotetext{
${ }^{1}$ Knight (1921) famously distinguished between "risk," which he argued is the situation where the distribution over a set of events is known, and "uncertainty," where the distribution over a set of events is not known. In Knight's language, rolling dice is risky; betting on a future war is uncertain. Nowadays, much of the literature has moved toward calling the later phenomenon "ambiguity," and uses "uncertainty" to denote situations where distributions are known. See Epstein (1999) and Epstein and Schneider (2007) as examples of such a practice. We will follow the more recent convention in our paper.
} 
We will organize the rest of our exposition as follows. Section 2 will document some basic time-series evidence that justifies the study of uncertainty shocks. Section 3 will review the different mechanisms that relate uncertainty shocks and aggregate variables in equilibrium models of the business cycle. Section 4 will discuss how to model uncertainty shocks. Section 5 will present a real business cycle model with financial frictions and time-varying uncertainty. Sections 6 and 7 will explain the computation and calibration of the model, including several methodological points of interest about how to handle the inherent non-linearities of models with uncertainty shocks. Section 8 will report our quantitative results. Section 9 will offer some concluding remarks and propose lines of future research.

\section{Why uncertainty shocks}

Nearly every time series in macroeconomics displays time-varying volatility, that is, a standard deviation that changes over time instead of being stationary (Engle, 1982). To illustrate this point, we will work with three time series: i) a time series that is representative of aggregate real variables (output growth); ii) a time series that is representative of prices (the GDP deflator); and iii) a time series that is representative of policy instruments (the federal funds rate). However, these three series are just examples. Plenty of other series of interest, from risk premia or exchange rates to unemployment or tax rates, display similar features. Fernández-Villaverde et al. (2011) and Fernández-Villaverde et al. (2015a) show many more examples. ${ }^{2}$

Panel 1a of Figure 1 plots the absolute value of GDP growth in the U.S. after World War II (we take absolute values to focus on volatility, not signs). Even the most casual observer can see that output growth fluctuates less at the end of the series than at the start.

This observation is clearer in Panel 1b, where we plot a 10-year moving average standard deviation of the same series. This moving average standard deviation is a measure of the realized volatility of output growth. ${ }^{3}$ Especially during the 1980s, the realized volatility of output dropped at a fast pace and it has stayed low since then, even after the convulsions of the financial crisis of 2007-2008. This is, of course, the "great moderation" of business cycle fluctuations (Stock and Watson, 2003, and Bernanke, 2004), which Panels 1a and 1b show is alive and enjoying excellent health.

\footnotetext{
${ }^{2}$ Bloom (2014) summarizes related and quite similar evidence regarding micro time series (e.g., the dispersion of firms' productivity, wages, income, etc.), but given the thrust of our paper, we will omit their discussion. Suffice it to say that the macro and micro evidence is highly complementary.

${ }^{3}$ Although both concepts are often mixed, it is useful to remember the difference between uncertainty about future volatilities (a forward-looking variable) and the realized volatility of past observations (a backward-looking variable). See Bollerslev et al. (2009) for an application based on this distinction.
} 
An alternative way to report the same finding is to compute the kernel densities of output growth before and after 1984.Q1 (a conventional start of the "great moderation"). Panel 1c of Figure 1 shows a much more concentrated density after 1984, with thinner tails. See Kim and Nelson (1999) and McConnell and Pérez-Quirós (2000), for similar findings about the change in volatility in the mid-1980s.

Figure 1: GDP growth

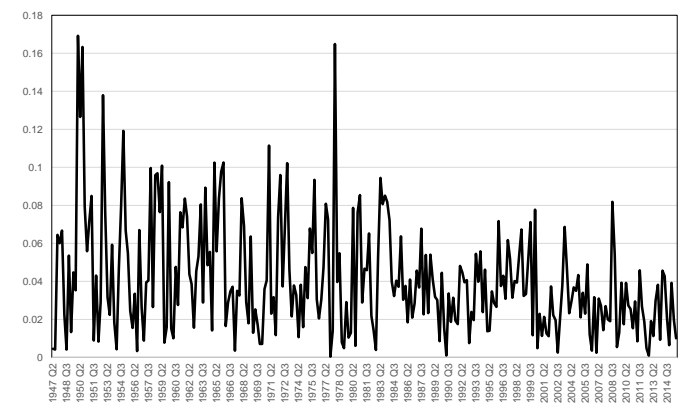

(a) Absolute value of GDP growth

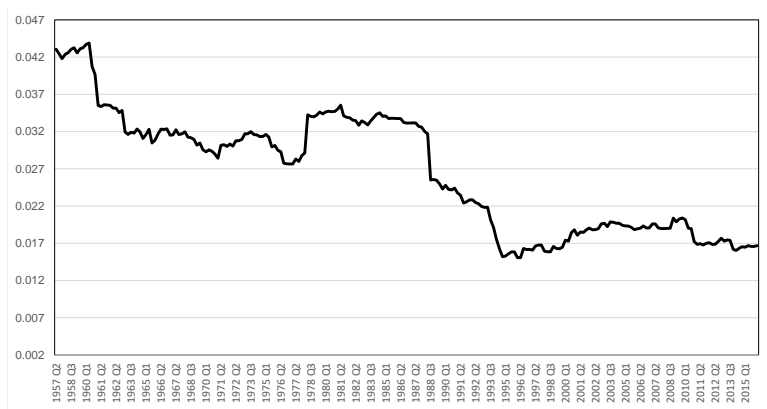

(b) Moving average standard deviation

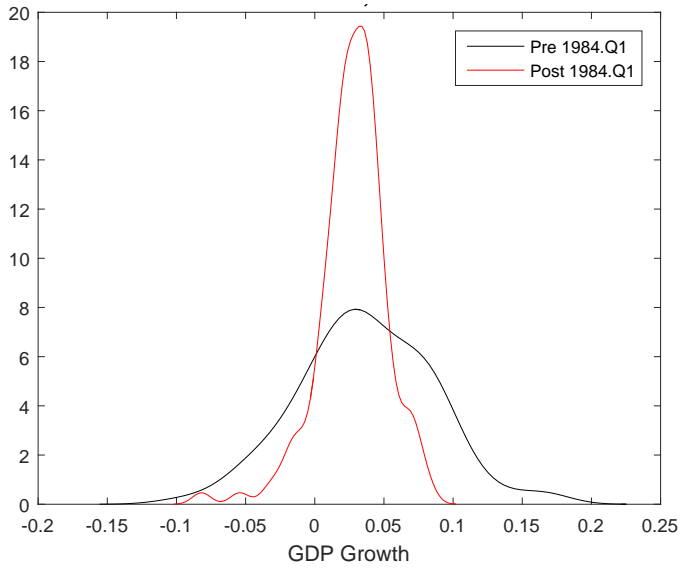

(c) Kernel densities of GDP growth

Figures 2 and 3 show the same results, but now with respect to the GDP deflator and the federal funds rate, respectively. Figure 2 documents the big spike of inflation in the 1960s, the only substantial peace-time inflation in U.S. history, and its "conquest" in the 1980s (Sargent, 1999). Figure 3 tells us a similar story, but even more sharply, with the period of zero (or close-to-zero) nominal interest rates at the end.

As we mentioned before, the same properties of time-variation in volatility appear in many other time series. The literature on uncertainty shocks has paid close attention to financial variables (see Bloom, 2009, Jurado et al., 2015, and Arellano et al., 2019, among several others) and to eliciting how financial-market uncertainty interacts with the real sector 
of the economy. This point is essential to remember as our model, later on, will place financial frictions at the center of its dynamics.

Figure 2: GDP deflator

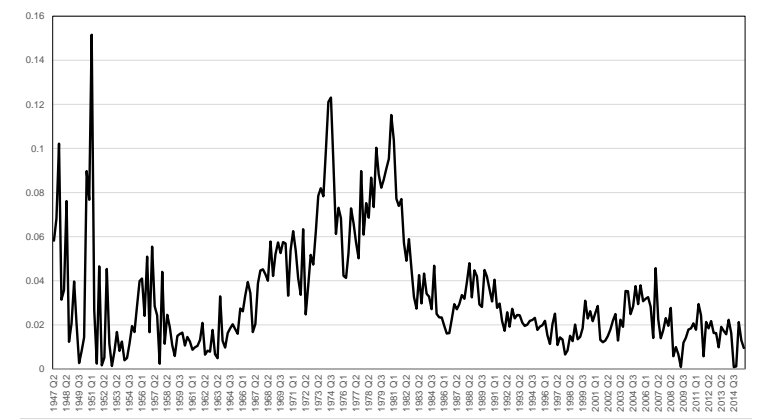

(a) Absolute value of GDP deflator

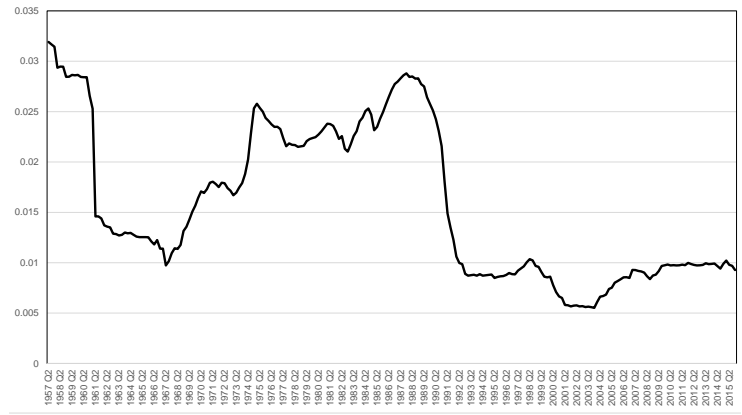

(b) Moving average standard deviation

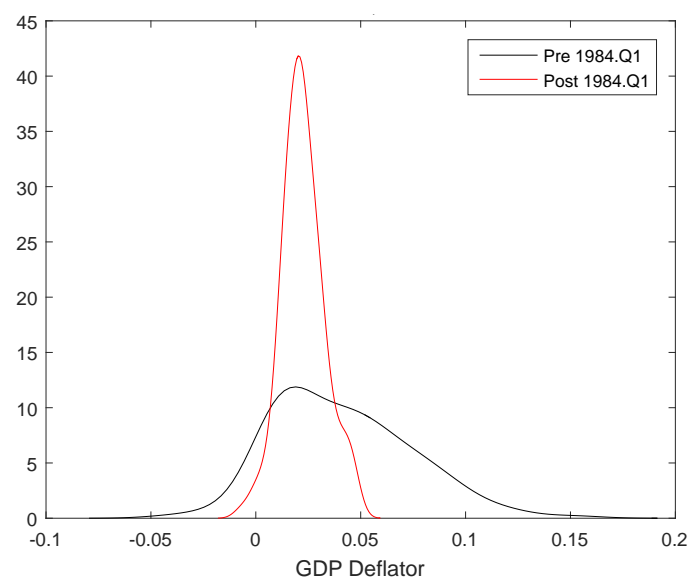

(c) Kernel densities of the GDP deflator

How can we think about these changes in the volatility of the time series over time? One possibility is to consider that the economy has undergone some form of structural transformation. For example, the move from manufacturing into services and improved supply-chain management might account for a lower volatility of output (Davis and Kahn, 2008). Similarly, financial innovations in the early 1990s might have stabilized the economy (Guerrón, 2009). And monetary policy might be conducted now with more deftness than in the past (Lubik and Schorfheide, 2004, and Cogley and Sargent, 2005).

However, there are so many examples of time-variation (with reversals in the direction of change!) that relying too much on structural transformation or better policies seems unwise. More importantly, when we try to capture the dynamics of macroeconomic time series with a vector autoregression (VAR) where we allow both for changes in the autoregressive coefficients and for variations in the matrix of variance-covariances of shocks, the likeli- 
hood function sharply prefers the latter as the primary driver of time-variation in volatility. This point was demonstrated in a classic paper by Sims and Zha (2006) and drove many researchers (including us!) into centering their study on changing standard deviations.

Figure 3: Federal funds rate

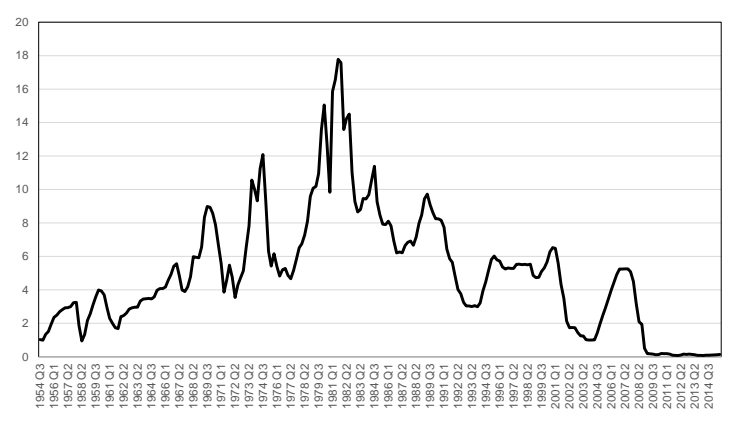

(a) Federal funds rate

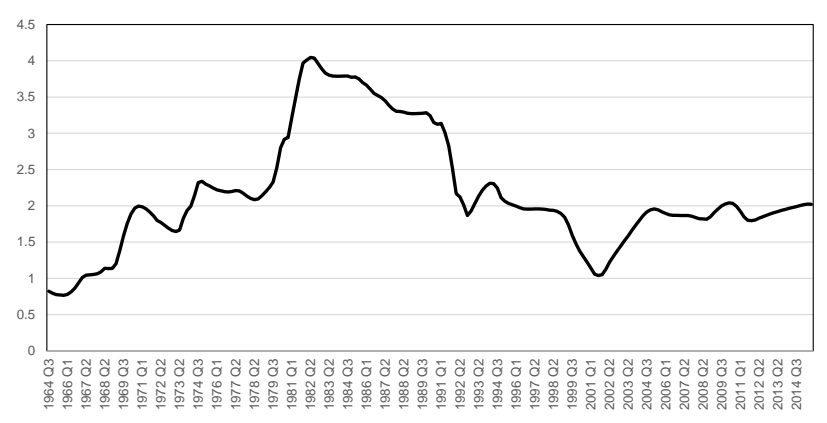

(b) Moving average standard deviation

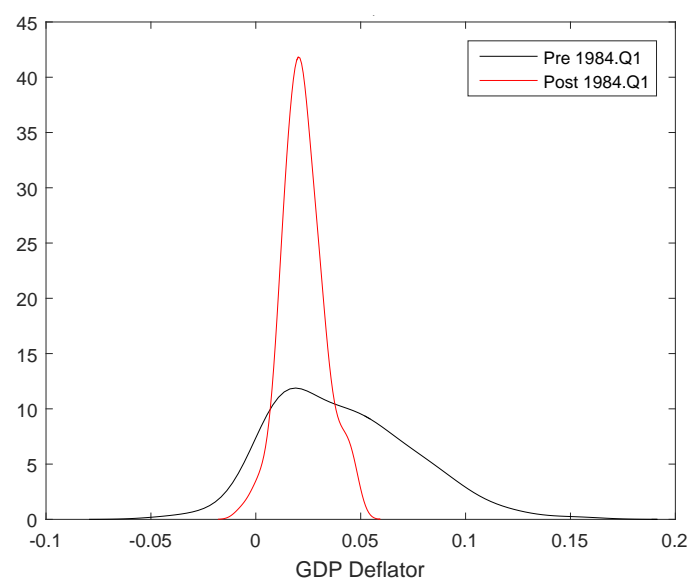

(c) Kernel densities of the federal funds rate

Thus, a more parsimonious approach is to consider that the shocks that induce aggregate fluctuations have time-varying volatility. Since a change in variance moves the dispersion of the future distributions of the shock, we can call these changes "uncertainty shocks," (or second-moment shocks) in comparison with more traditional shocks to levels (of productivity, preferences, tax rates, etc.; all of them first-moment shocks). In Section 4, we will return to the question of how to model these uncertainty shocks, and we will define them more precisely.

Unfortunately, uncertainty cannot be measured directly in the same way as output or inflation. We cannot open a financial newspaper or visit the webpage of a statistical agency and read about the uncertainty in the economy from a well-laid table. To discipline the uncertainty shocks that we can introduce in a model and gauge their quantitative significance, 
researchers need to come up with measures of uncertainty.

The two most popular approaches in the literature have been to estimate a formal econometric model and use it to back up a measure of realized volatility and future uncertainty or to use some proxy of uncertainty.

The first route, estimating a formal econometric model, is followed by Fernández-Villaverde et al. (2011) and Fernández-Villaverde et al. (2015a). These papers propose a stochastic volatility process for the variables of interest (such as interest rates, risk premia, or tax rates) and estimate such a process using the likelihood approach (see Fernández-Villaverde et al., 2016, for methodological details). Section 4 will explain why a stochastic volatility process is a natural process to be taken to the data.

The second route is to search for a proxy of uncertainty. Bloom (2009) popularized the idea of using the VIX index of 30-day implied volatility on the S\&P 500 stock market index. This proposal, however, has been criticized because it is hard to determine the direction of causality. Instead of uncertainty shocks triggering aggregate fluctuations, we can have aggregate fluctuations generating time-varying volatility in the stock market (in fact, given a standard stochastic discount factor model of asset pricing, part of the variance in the stock market should be the product of level shocks). More in general, an alternative reading of Figures 1-3 is that economic fluctuations cause uncertainty to increase, not the other way around. ${ }^{4}$

A more direct proxy can be to count occurrences of events related to uncertainty. In an influential paper, Bloom et al. (2016) proposed building policy uncertainty indexes through the aggregation of three components. The first component counts words related to uncertainty in newspaper articles. More words such as "uncertainty," "unknowns," and similar in any given period mean higher uncertainty. The second component counts the number of federal tax code provisions set to expire in future years: more tax code provisions set to expire means more uncertainty about future policies. The third component uses disagreement among economic forecasters as a proxy for uncertainty.

The idea of counting words related to uncertainty in newspaper articles has proven to be particularly popular. It is easy to do with modern statistical packages and search engines, and it can be combined with natural language processing, a booming sub-field of machine learning (see Blei et al., 2003, and, applied to uncertainty, Larsen, 2017).

Figure 4 shows an example of such a news index. Panel 4 a plots, in blue, the European monthly index built by Scott R. Baker, Nicholas Bloom, and Steven Davis using articles from Le Monde and Le Figaro for France, Handelsblatt and Frankfurter Allgemeine Zeitung

\footnotetext{
${ }^{4}$ Bekaert et al. (2013) show evidence that, indeed, uncertainty shocks drive much of VIX volatility. Nevertheless, we will return to the issue of the endogeneity of uncertainty in Section 9.
} 
for Germany, Corriere Della Sera and La Stampa for Italy, El Mundo and El Pais for Spain, and The Times of London and Financial Times for the United Kingdom. ${ }^{5}$ The same panel also plots, in red, the index for Spain between 2001:1 and 2016:1. Shaded areas show local peaks of uncertainty.

Panel 4b plots the kernel of the Spanish index and points out well-known political events in Spain during the period. For instance, we see that the times of highest uncertainty were related to the Iraq War and the Prestige oil spill (which severely damaged the reputation of the government due to its perceived mismanagement of the accident). The uncertainty at the time was at the 99th percentile of the distribution. We also see that the uncertainty distribution is asymmetric, and it has a long right tail. In Section 8, we will see how this evidence of long tails motivates the study of two-standard-deviation uncertainty shocks.

Figure 4: News

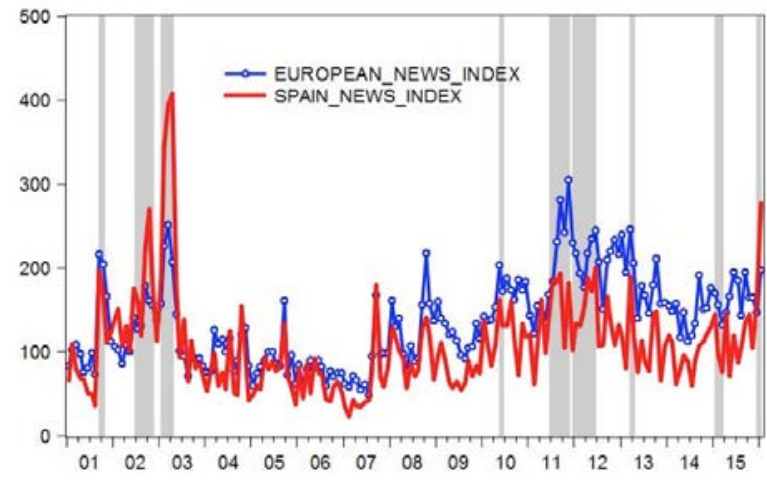

(a) News index

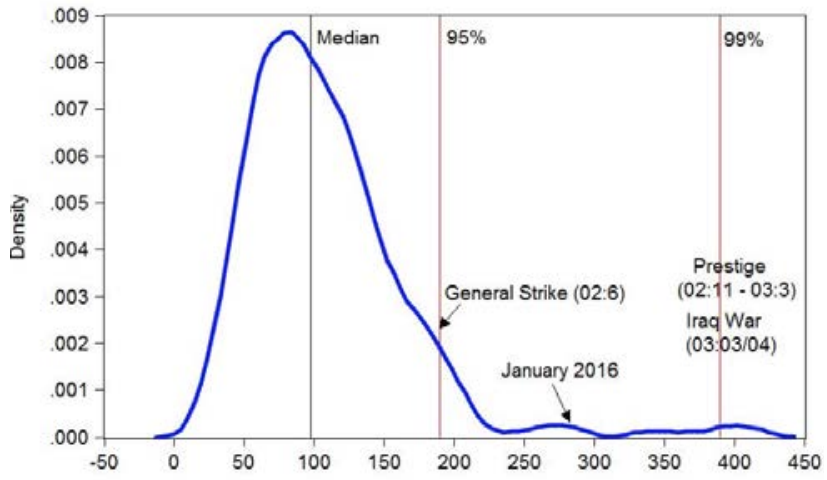

(b) Kernel density

One can easily relate peaks and drops in the news index with changes in economic activity (for instance, with a simple VAR or local projections) and obtain an estimate of the effects of this news on output, inflation, and other variables of interest. See Bloom (2009) and Bloom et al. (2016) for examples of well-known measurement estimation along those lines.

The question is, therefore, how to build mechanisms that link these empirical patterns with standard economic theory.

\section{Different mechanisms}

Many mechanisms link uncertainty and its variation over time with aggregate fluctuations in economic models. Instead of reviewing each of them in detail, we will focus on three

\footnotetext{
${ }^{5}$ See, for details and updates, http://www.policyuncertainty.com/europe_monthly.html.
} 
mechanisms that we consider the most important given the model with financial frictions that we present in Section 5. The first mechanism will be precautionary behavior. The second mechanism will be the Oi-Hartman-Abel effect. The third mechanism will be the real rigidities caused by financial frictions.

For those readers interested in complementing our exposition, Fernández-Villaverde and Rubio-Ramírez (2013) and Bloom (2014) are two concise reviews of the literature on uncertainty and business cycles up to its development a few years ago. These reviews dig deeper than we do into the microfoundations of why uncertainty may vary over time. Note also that, to keep the paper at a reasonable length, we will focus on the effect of uncertainty shocks in models with a representative agent and only discuss the implications of uncertainty shocks in models with heterogeneous agents in passing. Similarly, we will ignore the literature that relates uncertainty and long-run growth (for example, through the incentives to innovate in models of endogenous growth). See Aghion and Banerjee (2005) for more details on such a subfield.

\subsection{Precautionary behavior}

The most transparent mechanism to link uncertainty shocks and business cycles is to have agents in the model whose preferences display precautionary behavior. When the utility function of an economic agent (usually an individual but, if we ignore for a moment the issues of aggregation, also a household, a firm, or another group) is concave, the agent dislikes uncertainty. Expected utility from consumption is lower than the utility from expected consumption:

$$
\mathbb{E} u(c)<u(\mathbb{E}(c))
$$

where $\mathbb{E}$ is the expectation operator, $u(\cdot)$ is the utility function, and $c$ is consumption (which might be a vector of goods including services from durables, home production, and leisure, not just a scalar). Therefore, mean-preserving increases in the distribution of $c$ will lower expected utility.

However, risk aversion does not necessarily imply that economic agents will behave differently (i.e., they will display precautionary behavior) than in the absence of uncertainty. A trivial example is to consider an endowment economy, where the stochastic process for $c$ is exogenously given. Prices in equilibrium will move in such a way that the level of consumption will always be equal to the endowment, regardless of the level of uncertainty in the endowment. ${ }^{6}$

\footnotetext{
${ }^{6}$ Certainty equivalence does not mean that studying uncertainty is pointless in this class of models. As mentioned in the main text, since markets must clear, changes in uncertainty in an endowment economy will impact the valuation of assets that define claims to the stream of consumption. Similarly, there will be
} 
A more sophisticated example is the celebrated result of certainty equivalence first documented by Simon (1956) and Theil (1957). These researchers showed how, under some conditions on the objective function and the constraint set of a dynamic programming problem, the optimal action of a decision-maker under uncertainty who maximizes her expected utility is identical with the action that neglects uncertainty by maximizing utility under perfect foresight. Certainty equivalence will hold, for instance, when the objective function is quadratic and the constraints are linear. This may occur in the original formulation of the problem or it may appear as a consequence of a solution algorithm, such as the linear-quadratic approximation in Kydland and Prescott (1982), which yields a certainty equivalence solution (even when the original problem does not).

Leland (1968) and Sandmo (1970) broke this certainty equivalence property by showing that a sufficient condition for risk aversion to translate into precautionary behavior is the convexity of marginal utility. In this case, agents want to avoid large fluctuations in marginal utility across states of the world by saving a buffer stock of assets. Mathematically, risk aversion depends on the sign of the second derivative of the utility function (a negative sign means the agent is risk-averse). Precautionary behavior, instead, depends on the third derivative. In particular, agents will save more, everything else equal, if the third derivative of the utility function is positive (this is also known as "prudence"). ${ }^{7}$

Table 1: Utility functions and derivatives

\begin{tabular}{|c|c|c|}
\hline & Quadratic & CRRA \\
\hline Level & $\alpha_{1} c-\frac{\alpha_{2}}{2} c^{2}, \alpha_{1}, \alpha_{2}>0$ & $\frac{c^{1-\sigma}-1}{1-\sigma}, \sigma>0$ \\
\hline$u^{\prime}$ & $\alpha_{1}-\alpha_{2} c$ & $c^{-\sigma}$ \\
\hline$u^{\prime \prime}$ & $-\alpha_{2}$ & $-\sigma c^{-\sigma-1}$ \\
\hline$u^{\prime \prime \prime}$ & 0 & $(\sigma+1) \sigma c^{-\sigma-2}$ \\
\hline
\end{tabular}

To see this point, we can compare, in Table 1, two commonly used utility functions in macroeconomics: a quadratic utility function and a CRRA utility function. We will assume that consumption is positive and, in the case of the quadratic utility, below the satiation point $\frac{\alpha_{1}}{\alpha_{2}}$.

Both utility functions have positive first derivatives (i.e., more consumption is better than less) and negative second derivatives (i.e., agents are risk-averse). However, the third derivative of the linear-quadratic utility function is zero (i.e., we do not have precautionary

relevant welfare implications. After all, each exercise in asset pricing is, through the back door, an exercise in welfare analysis (Álvarez and Jermann, 2005).

${ }^{7}$ We keep repeating the caveat "everything else equal." This point matters. For instance, if the agents' demand for saving moves to the right due to precautionary behavior, their labor supply will also typically increase in general equilibrium. A higher labor income will increase consumption. 
behavior), but the third derivative of the CRRA utility function is positive (i.e., we have precautionary behavior). ${ }^{8}$ Note also how, for a CRRA utility function, the same parameter, $\sigma$, controls risk aversion and prudence (and, obviously, the elasticity of intertemporal substitution).

The extension of this explanation to the case with time-varying uncertainty is straightforward. Imagine that we have an uncertainty shock that increases the variance of productivity innovations, demand shifts, or fiscal and monetary policy changes. After an uncertainty shock, consumers with prudence will react by increasing their precautionary behavior, everything else equal.

What are the aggregate consequences of these changes in precautionary behavior? In a benchmark equilibrium business cycle model with flexible prices and a standard calibration, the effects are limited. With a CRRA utility function, precautionary behavior typically appears as precautionary saving. Thus, an increase in uncertainty leads to a higher demand for savings. But a higher demand for savings lowers the real interest rate that clears the investment-savings market. Often, and depending on the concrete details of the model, there is also a fall in demand for investment, which further lowers the interest rate. By inducing more consumption today, the lower interest rate undoes most of the contractionary effects of higher precautionary savings. See Basu and Bundick (2017) for a quantitative assessment of this mechanism.

This result also appears in models with heterogeneous agents and incomplete markets (Heathcote et al., 2009). In this class of environments, an increase in uncertainty, either at an individual or aggregate level, leads to increases in aggregate savings and a lower interest rate. The effect on the cross-sectional distribution of wealth is, however, contingent on the calibration of the model. For instance, the persistence of the shocks to income is key to determining how agents will react to changes in uncertainty. When shocks are very persistent, higher uncertainty might translate into significant increases in precautionary behavior and aggregate allocations.

How can we get around this quantitative irrelevance result of time-variations in uncertainty? Our previous description of this result lays out a map of the different possibilities in front of researchers: selecting different parameter values, having several assets, and introducing nominal rigidities.

\footnotetext{
${ }^{8}$ This point also illustrates why the first-order perturbation of an equilibrium business cycle around the deterministic steady state is certainty equivalent (Fernández-Villaverde et al., 2016). A first-order perturbation only uses information about the first and second derivative of the utility function (we take derivatives of an Euler equation, which has a first derivative itself). Given a CRRA utility function with parameter $\sigma$ and a steady-state consumption $c_{s s}$, we can calibrate $\alpha_{1}=(1+\sigma) c_{s s}^{-\sigma}$ and $\alpha_{2}=\sigma c_{s s}^{-\sigma-1}$. With this calibration, the quadratic utility function and the CRRA would have the same first and second derivatives at $c_{s s}$ and, thus, a first-order perturbation must deliver the same answer for both utilities.
} 


\subsubsection{Different parameter values}

The first possibility is to move away from standard parameter values, either by increasing risk aversion or the size of the change in uncertainty. The latter can be accomplished by selecting different target moments in a calibration or by modifying the specification of the model and the associated likelihood function.

Higher risk aversion can be achieved, for example, by using recursive preferences à la Epstein and Zin (1989). With these preferences, we can select parameters that deliver high risk aversion -and with it, high and varying risk premia- while keeping the relatively high intertemporal elasticities of substitution needed to ensure sound business cycle properties for the model (see Tallarini, 2000, for a documentation of this "quasi-separation" of prices and quantities) ${ }^{9}$

An even more radical departure from standard models than using Epstein-Zin preferences is to move to a specification of preferences that displays explicit ambiguity aversion as in Gilboa and Schmeidler (1989), Epstein (1999), and Epstein and Schneider (2007). Here, we can think about changes in uncertainty as being reflected in changes in the range of the multiple priors that an agent considers. Since usually in these models agents adopt a maxmin policy rule that leads them to behave as if under a worst-case scenario, an increase in the range of priors is, loosely speaking, equivalent to the agents believing that some parameter or some shock will take its worst possible realization. Two notable examples of such a line of research are Ilut and Schneider (2014) and Bianchi et al. (2017). Since there is a link between Epstein-Zin preferences, concerns for robustness, and ambiguity aversion, most of the ideas in these last two paragraphs apply to each of three situations (Barillas et al., 2009, Maccheroni et al., 2006, and Strzalecki, 2013).

We can obtain higher uncertainty by increasing the probability of rare disasters (a small risk of a large macroeconomic shock), as argued in Gabaix (2012). We can think about rare disasters as the possibility of a war, a natural catastrophe, a pandemic, or massive political upheavals that disrupt economic activity. ${ }^{10}$ For instance, a rare disaster uncertainty shock can be a sudden change in geopolitical factors that increases the probability of a war in the near future, changes in climate that make a devastating flood in a coastal country more likely, or the appearance of a previously unknown virus that raises the chances of a major global pandemic.

\footnotetext{
${ }^{9}$ See also Swanson (2012) for an important insight about how to compute risk aversion in models with endogenous labor supply.

${ }^{10}$ Barro (2006), Barro and Ursúa (2008), Gabaix (2011), and Gourio (2012) have emphasized the importance of tail-end risk -in particular, disaster risk- as a driver of aggregate fluctuations and asset pricing. Note, however, that here we are not discussing the effects of these tail-end shocks, but the impact of changes in the probability of one of those shocks arriving in any given period.
} 
In asset pricing, Bansal and Yaron (2004) illustrate how the combination of recursive preferences, a small long-run predictable component, and stochastic volatility on the consumption endowment can account for the equity premium, the risk-free rate, and the volatility of the market return, risk-free rate, and the price-dividend ratio. This message is reinforced by Drechsler and Yaron (2011), who document a quantitatively significant role for transient non-Gaussian shocks to fundamentals that affect agents' views of economic uncertainty and asset prices.

Fernández-Villaverde and Levintal (2018) make a similar point in the context of both standard real business cycle and fully fledged New Keynesian models. Even in the presence of production, Epstein-Zin preferences and rare disasters can match basic asset pricing observations while delivering excellent business cycle properties.

\subsubsection{One-sided shocks}

Motivated by our previous discussion, one can think about a change in the probability of a rare disaster as a change in the skewness of the distribution of shocks. Thus, a possible area of research, much unexplored, is to consider skewness shocks. Most increases in uncertainty in the real world are one-sided. A financial crisis increases the probabilities of a major recession, but not the probabilities of an unseen boom. And a pandemic usually means there is much more downside health risk, but it rarely means there is a simultaneous higher probability of much better health outcomes.

A quick-and-dirty way to get a first approximation of this problem in an equilibrium business cycle model is to consider a simultaneous negative level shock and a positive uncertainty shock (i.e., an increase in variance). This exercise, however, does not fully capture the shifting in distributions that we are envisioning.

In the context of models with heterogeneous firms, Salgado et al. (2019) have recently shown that a negative shock to the skewness of firms' productivity growth generates a persistent drop in output, investment, hiring, and consumption. Hopefully, more research will come from this direction in the near future.

\subsubsection{Several assets}

Much of the attenuation of the effects of uncertainty shocks comes from the fact that, in a standard neoclassical growth model (and its real business cycle and New Keynesian model variations), agents only have access to one asset in positive net supply: physical capital.

Why is the presence of only one asset key? Because when uncertainty increases and agents want to engage in more precautionary behavior, the only asset in which that precau- 
tionary behavior can be reflected -physical capital- also becomes typically riskier. Capital is riskier either because we have more productivity uncertainty or its valuation becomes riskier (for example, because of higher discount factor uncertainty). ${ }^{11}$ There are, therefore, two counterbalancing forces: a higher demand for capital, because of precautionary behavior, and a lower demand for capital, because of higher risk.

Fernández-Villaverde et al. (2011) show a straightforward path out of this effect: the presence of several assets. Specifically, Fernández-Villaverde et al. (2011) model open market economies where agents can also save in foreign assets. If we assume, for instance, that higher uncertainty in Spain does not translate into higher uncertainty in Japan (or that the correlation among these assets is less than 1), then Spanish agents can shift from Spanish assets into Japanese assets and self-insure against higher uncertainty. Through the induced changes that such a shift has on investment and labor supply both in Spain and in Japan, uncertainty shocks can have large real effects.

\subsubsection{Nominal frictions}

By preventing the counterbalancing effect of prices that attenuated the effects of uncertainty shocks above, nominal rigidities can increase the consequences of volatility and induce its own type of precautionary behavior.

A clear case is Fernández-Villaverde et al. (2015a). In this paper, firms encounter nominal rigidities while setting up prices: they need to set up a price before seeing the realization of shocks and must pay a cost to change it. Firms are more worried about setting a relative price that is too low ex-post than too high. A relative price that is too low ex-post forces the firm to sell too much at an unfavorable price (New Keynesian models assume a full-service obligation at posted prices). A relative price that is too high ex-post, instead, compensates for the low sales with a high margin. In other words, the profit function is asymmetric with respect to the relative price: it falls more quickly to the right of the optimal relative price than to the left. The strength of this effect depends positively on the elasticity of substitution among goods.

A higher level of uncertainty, by increasing the dispersion of where the relative price will fall ex-post, induces an upward pricing bias. Firms will increase their expected mark-up and, thus, reduce the percentage of times their relative prices are too low ex-post. However, a higher mark-up increases the distortions in the economy, lowering output, hours worked, investment, and consumption. This last point is remarkable. In many other models of uncertainty shocks, firms are induced to lower investment after uncertainty spikes. However,

\footnotetext{
${ }^{11}$ This statement, however, must be qualified: in some particular models, an increase in uncertainty might not affect the riskiness of capital, although, as we mentioned in the main text, it typically does.
} 
since the economy is as productive in the current period as before, consumption must increase to clear markets. Higher consumption is, however, counterfactual. By highlighting the role of the upward pricing bias and the distortions it creates in allocation, Fernández-Villaverde et al. (2015a) can fix this problem.

\subsection{The Oi-Hartman-Abel effect}

In the previous subsection, we focused on precautionary behavior, typically in the form of saving and pricing decisions. We now analyze how uncertainty can affect the production decisions of the economy. We will discuss first the Oi-Hartman-Abel effect and, in the next subsection, the consequences of real rigidities.

Our starting point for doing so is to go back to Oi (1961), Hartman (1972), and Abel (1983). Imagine that we have a firm that uses capital, $k_{t}$, rented at rate $r_{t}$, and labor, $l_{t}$, paid at wage $w_{t}$ to produce a final good $y_{t}$ with a Cobb-Douglas production function

$$
y_{t}=A_{t} k_{t}^{\alpha} l_{t}^{\beta}
$$

where $A_{t}$ is the productivity level at period $t$. Assume as well that the production function shows decreasing-returns-to-scale $\alpha+\beta<1$. The optimality conditions for the firm are:

$$
\begin{aligned}
k_{t}^{*} & =\psi_{1} A_{t}^{\frac{1}{1-\alpha-\beta}} \\
l_{t}^{*} & =\psi_{2} A_{t}^{\frac{1}{1-\alpha-\beta}}
\end{aligned}
$$

where $\psi_{1}=\left(\frac{\alpha}{r_{t}}\right)^{\frac{1-\beta}{1-\alpha-\beta}}\left(\frac{\beta}{w_{t}}\right)^{\frac{\beta}{1-\alpha-\beta}}$ and $\psi_{2}=\left(\frac{\alpha}{r_{t}}\right)^{\frac{\alpha}{1-\alpha-\beta}}\left(\frac{\beta}{w_{t}}\right)^{\frac{1-\alpha}{1-\alpha-\beta}}$.

These optimality conditions lead to a period profit:

$$
\Pi_{t}^{*}=\psi_{3} A_{t}^{\frac{1}{1-\alpha-\beta}}
$$

where $\psi_{3}=\psi_{1}^{\alpha} \psi_{2}^{\beta}-\psi_{1} r_{t}-\psi_{2} w_{t}$

These results show how the input demands and profits are convex on $A_{t}$. Thus, a meanpreserving increase in the uncertainty regarding $A_{t}$ will increase, everything else equal, the ex-post dispersion of input demands, profits, and output.

The key in this example is that the firm, by endogenously choosing its size, can take advantage of a higher volatility. When good shocks arrive, the firm can expand, and when bad shocks arrive, the firm can contract. The concavity of the production function ensures that such decision rules deliver higher profits when $A_{t}$ fluctuates due to uncertainty shocks 
than when $A_{t}$ is constant. ${ }^{12}$

Interestingly, the closer the firm is to constant-returns-to-scale, the larger is the effect, until it completely collapses when we reach $\alpha+\beta=1$ and the size of the firm becomes indeterminate. However, if there are adjustment costs to capital or some other friction that prevents a constant-returns-to-scale firm from fully adjusting to shocks, we will recover a "quasi-Oi-Hartman-Abel effect." This mechanism will appear, later on, with the quantitative results of our model. On the other hand, if the inputs are entirely fixed, for instance, because we have a putty-clay technology as in Gilchrist and Williams (2000), the effect will disappear.

\subsection{Real frictions}

The most common real friction in models with uncertainty shocks is the presence of non-convex adjustment costs in investment (Bloom, 2009). When we have these adjustment costs, firms follow $S s$ rules. Firms have a band of inactivity where they do not adjust their capital. If the shocks move the target capital too far away from the existing capital (that is, the firm moves outside the $S s$ band), the firm will incur the non-convex adjustment cost and invest.

Bloom (2009) points out that if uncertainty about the future increases, the $S s$ band will become wider, as firms want to be more cautious before readjusting capital. Then, in the short run, fewer firms will move outside the $S s$ band, and investment will fall. The effect will be particularly salient if the distribution of firms has a lot of mass close to the bands, perhaps due to some past aggregate shocks. In the absence of an uncertainty shock, many of these firms would have jumped out of the band in the current period.

However, since the economy is still as productive as before, consumption must increase to clear markets (recall our discussion above when we analyzed nominal frictions). Thus, one needs to enrich the model with mechanisms that prevent this counterfactual increase in consumption.

In our model in Section 5, we will tackle a different real friction that has received less attention: financial frictions. By changing the distribution of future realizations, uncertainty shocks modify the probability of a financial friction binding in the future (or the severity of the constraint). Thus, economic agents will undertake actions today to protect themselves

\footnotetext{
${ }^{12}$ In fact, a similar phenomenon can appear on the household side in a standard real business cycle model. Since the household can adjust its labor supply after a productivity shock, even with a concave utility function, expected utility can be higher with more uncertainty than with less. The intuition is that, while the direct utility function is concave in its inputs, the indirect utility function can be convex in prices. See Cho et al. (2015) for a quantitative exploration of this point and an example of a simple economy where business cycles increase welfare. In addition, this result should make us cautious about interpolating the welfare costs of business cycles, including uncertainty shocks, derived from endowment economies à la Lucas (1985) into production economies. This comment, of course, has sharp consequences for asset prices as well.
} 
against such realizations. For example, if capital provides liquidity services that are particularly valuable when the financial constraints are more severe, the agents will increase their investment in the current period in the shape of "precautionary investment" (a close relative of the option value effect of Bernanke, 1983, and Dixit and Pindyck, 1994). We will return to these ideas in Section 8.

\section{How to model uncertainty shocks}

The next question we face is how to model, in a simple yet effective way, the changes in uncertainty over time. To make things more concrete, imagine that we have the volatility, $\sigma_{t}$, of some random variable of interest $x_{t}$, such as productivity or a preference shifter, that evolves as:

$$
x_{t}=\rho x_{t-1}+e^{\sigma_{t}} \varepsilon_{t}, \text { where } \varepsilon_{t} \sim \mathcal{N}(0,1) .
$$

To simplify the exposition, we are assuming that $x_{t}$ follows an $\mathrm{AR}(1)$, but the extension to more general structures is straightforward.

The literature has identified three main alternatives to specify $\sigma_{t}$ : stochastic volatility, GARCH processes, and Markov-regime switching. Stochastic volatility (SV) models the evolution of $\sigma_{t}$ as an ARMA process, often an $\operatorname{AR}(1)$ of the form:

$$
\sigma_{t}=\left(1-\rho_{\sigma}\right) \sigma+\rho_{\sigma} \sigma_{t-1}+\left(1-\rho_{\sigma}^{2}\right)^{1 / 2} v u_{t}, \text { where } u_{t} \sim \mathcal{N}(0,1)
$$

The $\operatorname{AR}(1)$ is written in logs to ensure $\sigma_{t}>0 .{ }^{13}$ We will call $u_{t}$ the "uncertainty shocks" in contrast with the "level shock" $\varepsilon_{t}$. This neat separation between uncertainty and level shocks allows an easier isolation of the effects of the former in the data and in the equilibrium economic model. Also, we rescale the variance of the uncertainty shocks to make them invariant to changes in their persistence $\rho_{\sigma}$.

We usually assume that the uncertainty and level shocks are uncorrelated. Nevertheless, it is quite direct to correlate $\varepsilon_{t}$ and $u_{t}$ if needed (Fernández-Villaverde et al., 2011). This correlation is sometimes called the "leverage effect" of level shocks on uncertainty shocks because, in asset pricing, one can get this correlation through the presence of leverage in a firm's balance sheet. Also, nothing prevents us from having innovations that are not Gaussian, such as in Cúrdia et al. (2014). Since models with uncertainty shocks need to be solved with non-linear solution methods in any case, we can deal with a large class of distributions for the innovations.

\footnotetext{
${ }^{13} \mathrm{In}$ an alternative formulation, we can write the AR process as $x_{t}=\rho x_{t-1}+\sigma_{t} \varepsilon_{t}$ and model the evolution of $\sigma_{t}$ in logs.
} 
Many researchers are attracted to SV because of its simplicity. For example, with an $\mathrm{AR}(1)$ specification, we only have to deal with two new parameters: $\rho_{\sigma}$, the persistence of $\sigma_{t}$, and $v$, the standard deviation of the innovations to volatility ( $\sigma$, the mean of volatility, still needs to be estimated when we take volatility as constant). Also, SV models are easily estimated using sequential Monte Carlo methods, either by themselves or jointly with the rest of the equilibrium business cycle model (Fernández-Villaverde et al., 2016). As we will discuss later, sequential Monte Carlo methods are particularly well-adapted to massive parallelization.

Despite its parsimony, SV can capture much of the dynamics of the data. Also, the combination of exponents of $\sigma_{t}$ in equation (4) and levels in its evolution (5) shifts the distribution of the volatility into flexible shapes that can accommodate many time series. See Shephard and Andersen (2009) for a more complete discussion.

The second approach is to model $\sigma_{t}$ as a GARCH process (Bollerslev, 1986):

$$
\sigma_{t}^{2}=\omega+\alpha\left(\sigma_{t-1} \varepsilon_{t-1}\right)^{2}+\beta \sigma_{t-1}^{2}
$$

that is, the variance $\sigma_{t}^{2}$ is a function of its own past and the squared scaled innovation $\left(\left(\sigma_{t-1} \varepsilon_{t-1}\right)^{2}\right)$. As we argued with SV, instead of our simple GARCH specification, we could think about much richer structures as in the many incarnations of GARCHs proposed in econometrics (Bollerslev, 2008).

The main difference between SV and GARCH is that, in the latter, there is only one shock, $\varepsilon_{t}$, driving the dynamics of the level and volatility of $x_{t}$. Therefore, it is impossible to separate a volatility shock from a level shock: higher volatilities are triggered only by large past level innovations.

In reduced-form time series econometrics, since we are mainly concerned with forecasting, this constraint is not much of an issue. However, when we deal with equilibrium business cycle models, the assumption is too restrictive. Furthermore, while estimating time-series GARCHs is much easier than estimating an SV model, solving an equilibrium business cycle model with either GARCH or SV shocks is roughly equivalent in terms of complexity. Finally, SV models tend to do better in terms of fitting the data (Nakajima, 2012). Therefore, we see GARCH specifications as clearly dominated by SV for studying uncertainty shocks in dynamic macroeconomics and we will not discuss them further.

The third approach to modeling the evolution of $\sigma_{t}$ is to specify a Markov regimeswitching structure. For instance, we can assume that $\sigma_{t}$ follows a Markov chain that takes two values, $\sigma^{L}$ and $\sigma^{H}$, where $L$ stands for low uncertainty and $H$ stands for high uncertainty 
$\left(\sigma^{L}<\sigma^{H}\right)$. The transition matrix is, then:

$$
\left(\begin{array}{cc}
a_{1} & 1-a_{1} \\
1-a_{2} & a_{2}
\end{array}\right)
$$

Even with only two points, different choices of $a_{1}$ and $a_{2}$ capture a large range of interesting behaviors. A typical example is calibrating $a_{1} \gg a_{2}$, which can be read as low uncertainty being the regular times and high uncertainty as the rare times (this is similar to our idea of rare disasters in Section 3, but now in terms of uncertainty). Extending the Markov chain process to an arbitrary $n$ number of points (or even to induce variation in the entries of the transition matrix) to encompass a much richer set of events is straightforward (Hamilton, 2016).

How do we compare SV and Markov regime-switching models? There is no obviously superior approach. SV assumes that uncertainty varies as a continuously changing process. Markov regime-switching models evolve more abruptly, with discrete jumps interrupted by periods of constant uncertainty.

Some researchers can argue that a continuously changing process better reflects their reading of the evidence. For example, the uncertainty about future fiscal policy might evolve daily as news about the state of the economy arrives or the political game in Congress unravels day-by-day. Other researchers can reply that some events are better characterized as discrete jumps, such as the election of a new president or the appointment of a new governor of a central bank.

Many time series of interest probably share both continuous and discrete components, and we could consider an encompassing model where the change in the standard deviation is given by:

$$
\sigma_{t}=\nu_{t}+\left(1-\rho_{\sigma}\right) \sigma+\rho_{\sigma} \sigma_{t-1}+\left(1-\rho_{\sigma}^{2}\right)^{1 / 2} v u_{t}
$$

where is $\nu_{t}$ is a discrete jump with a Bernoulli scheme distribution (this class of models is popular in finance; see Bates, 1996).

The challenge for this encompassing specification is that with fewer than 300 observations, as we have in the U.S. national income and product accounts (and much fewer for other countries), estimating such a model is a tall order.

A small technical advantage of the SV specification is that we can take derivatives with respect to the volatility level, which we cannot in a Markov regime-switching specification. Taking derivatives will be convenient when, in Section 6, we defend the use of perturbation methods to solve equilibrium models with uncertainty shocks. This advantage will make us opt for $\mathrm{SV}$ in the model in the next section. 
On the other hand, SV has its own problems. For instance, if the real process has a discrete jump, the SV specification will "anticipate" the change by showing changes in volatility before they happen (Diebold, 1986). The likelihood function (or most other estimating functions) dislikes huge changes in one period and prefers a sequence of smaller $u_{t}$ before and after the actual change to an exceptionally large $u_{t}$ that would account for the jump.

We are now finally ready to introduce our real business cycle model with financial frictions and uncertainty shocks.

\section{Our model}

To illustrate the impact of uncertainty shocks on aggregate fluctuations, we propose a standard real business cycle model augmented with a financial friction in the tradition of Kiyotaki and Moore (1997). ${ }^{14}$ In this economy, time is discrete, and there is a continuum of households with measure one. Each household has a unit mass of members who are $e x$ ante identical. However, in the middle of every period, family members are separated into entrepreneurs and workers. Each member receives a shock that determines her role within the period (Shi, 2015). An individual can be an entrepreneur with probability $\pi$ or a worker with probability $1-\pi$. An entrepreneur can invest in capital, but she does not work. In comparison, a worker cannot invest, but she can work. Both entrepreneurs and workers can trade equity claims in the financial market subject to constraints to be specified below. Occupations are assigned for one period only. In the next period, all the members' identities are reshuffled.

For parsimony, we will introduce only three level shocks in the model: i) a "supplyside" productivity shock; ii) a "demand-side" preference shock; and iii) a "real-rigidity" financial friction shock. Associated with each of these three level shocks, we will have their corresponding three uncertainty shocks for a total of six shocks. While six shocks might not be enough to capture all the dynamics in the data, it will be sufficient to illustrate the main mechanisms that link uncertainty shocks with aggregate fluctuations and that we explained in Section 3. Other supply, demand, or rigidity shocks (such as price and wage stickiness) will, to no small extent, behave in similar ways and we can skip them in the interest of transparency (see Fernández-Villaverde et al., 2015a, and Justiniano and Primiceri, 2008, for much richer models with uncertainty shocks).

\footnotetext{
${ }^{14}$ Our description of the model follows closely Guerrón-Quintana and Jinnai (2019b).
} 


\subsection{Three stages}

A period is divided into three stages: i) decision making by the household; ii) production; and iii) consumption and investment. In the decision stage, all members of the household start the period united and share their assets, which are equal to $s_{t}$ equity claims. One equity claim, with price $q_{t}$, gives its holder the ownership of one unit of capital. Thus, $s_{t}$ is also the total amount of capital of the household and $q_{t} s_{t}$ its valuation.

Next, the aggregate shocks to exogenous state variables are realized. Because, at this stage, all the members of the household are identical, the head of the household divides the equity claims among the members evenly. These members also receive contingency plans to follow after they are assigned roles. If the agent becomes an entrepreneur, she would invest $i_{t}$ units of the consumption good, consume $c_{t}^{e}$ units of the consumption good, and make necessary trades in the stock market to ensure that she would hold $s_{t+1}^{e}$ units of equity claims at the end of the period. In contrast, if the member becomes a worker, she would supply $l_{t}$ units of labor, consume $c_{t}^{w}$ units of the consumption good, and make necessary trades in the stock market to ensure that she would hold $s_{t+1}^{w}$ units of equity claims at the end of the period. We will discuss below how the head of the household decides these instructions. After receiving their directives, the members depart to the market. The members remain separated for the rest of the period.

At the beginning of the production stage, each member receives the shock whose realization determines whether the individual is an entrepreneur or a worker. Next, these members move to the input markets, and they rent their labor $l_{t}$ and capital services $u_{t} k_{t}$ to a representative competitive firm. The capital services $k_{t}^{D}$ are the product of the total units of capital, $k_{t}$, and its utilization rate, $u_{t}$. This utilization rate controls depreciation, $\delta\left(u_{t}\right)$. A higher utilization rate causes faster depreciation according to:

$$
\delta\left(u_{t}\right)=\delta_{0}+\delta_{1}\left(u_{t}-1\right)+\frac{\delta_{2}}{2}\left(u_{t}-1\right)^{2} .
$$

Here, $\delta_{i}>0$ for $i \in\{0,1,2\}$ and $\delta_{0}$ is depreciation in the steady state. In this formulation, we can have $u_{t}>1$, which we interpret as capital being used above the average rate for which it was designed.

The representative competitive firm produces a final good $y_{t}$ using the inputs rented from the members of the household with a constant-returns-to-scale Cobb-Douglas production technology:

$$
y_{t}=A_{t}\left(k_{t}^{D}\right)^{\alpha}\left(l_{t}\right)^{1-\alpha} .
$$

The final good can be used for consumption or, as we will describe momentarily, for invest- 
ment. Here, $A_{t}$ is a technology shock, which both households and firms take as given and evolves as an $\operatorname{AR}(1)$ process:

$$
A_{t}=\left(1-\rho_{A}\right) \bar{A}+\rho_{A} A_{t-1}+e^{\sigma_{A, t}} \epsilon_{A, t}, \text { where } \epsilon_{A, t} \sim \mathcal{N}(0,1) .
$$

We normalize the deterministic steady-state productivity $\bar{A}$ to 1 and impose the reflective barrier $A>0$. Given our calibration and the fact that we will focus on studying impulseresponse functions around the deterministic steady state, such a barrier is irrelevant in our computations. ${ }^{15}$

Equation (7) incorporates time-varying volatility into productivity $\sigma_{A, t}$. In particular, the volatility $\sigma_{A, t}$ also obeys an $\mathrm{AR}(1)$ process:

$$
\sigma_{A, t}=\left(1-\rho_{\sigma_{A}}\right) \sigma_{A}+\rho_{\sigma_{A}} \sigma_{A, t-1}+\left(1-\rho_{\sigma_{A}}^{2}\right)^{1 / 2} v_{A} u_{A, t}, \text { where } u_{A, t} \sim \mathcal{N}(0,1)
$$

with mean $\sigma_{A}$ and persistence $\rho_{\sigma_{A}}$. This is an example of the SV specification we discussed in Section 4 and that we argued is particularly convenient for equilibrium business cycle models. The innovation to volatility, $u_{A, t}$, is the first of the uncertainty shocks that we consider in this model and can be interpreted as a "supply-side" uncertainty shock.

Let $r_{t}$ and $w_{t}$ denote the rental price of capital and the wage rate, respectively. Therefore, the optimality conditions for the firm are the common equalities of marginal productivities of inputs to their prices:

$$
\alpha \frac{y_{t}}{k_{t}^{D}}=r_{t}
$$

and

$$
(1-\alpha) \frac{y_{t}}{l_{t}}=w_{t}
$$

After production, workers receive wage income, equity holders collect dividends, and a fraction $\delta\left(u_{t}\right)$ of capital depreciates.

In the third stage of the period, consumption takes place, and entrepreneurs seek finance to undertake investment projects. To do so, an entrepreneur has access to a linear technology that transforms $i_{t}$ units of the final good into $i_{t}$ units of new capital.

The period ends after the events in the three states. The members of the household get together, their identities are reset, and the next period begins.

\footnotetext{
${ }^{15}$ Note the absence of long-run growth in productivity. In a model such as this one, such an absence is of secondary importance. In the presence of a deterministic or stochastic trend in $A_{t}$, we can always rescale all variables by such a trend and obtain a stationary representation with properties nearly identical to the version of the model we study here.
} 


\subsection{Constraints of the head of the household}

The contingency plans that the head of the household provides to each member of the household must meet several constraints. First, the directives have to satisfy the budget constraints:

$$
c_{t}^{e}+i_{t}=r_{t} u_{t} s_{t}+q_{t}\left(\left(1-\delta\left(u_{t}\right)\right) s_{t}+i_{t}-s_{t+1}^{e}\right)
$$

and

$$
c_{t}^{w}=r_{t} u_{t} s_{t}+q_{t}\left(\left(1-\delta\left(u_{t}\right)\right) s_{t}-s_{t+1}^{w}\right)+w_{t} l_{t} .
$$

Equation (9) is the budget constraint of entrepreneurs. The equation says that the consumption of an entrepreneur $\left(c_{t}^{e}\right)$ plus her investment $\left(i_{t}\right)$ must be equal to the return from renting her equity holdings in the inputs market $\left(r_{t} u_{t} s_{t}\right)$ plus the value of her net equity trades $\left(q_{t}\left(\left(1-\delta\left(u_{t}\right)\right) s_{t}+i_{t}-s_{t+1}^{e}\right)\right)$. Equation (10) is the budget constraint workers face. Its interpretation is analogous to the interpretation of equation (9), except that now the worker does not invest and she has labor income $w_{t} l_{t}$.

Second, because the members of the household share their assets before the next period begins, the total equity position of the household must be equal to the sum of the positions of its members:

$$
s_{t+1}=\pi s_{t+1}^{e}+(1-\pi) s_{t+1}^{w} .
$$

Third, the directives cannot avoid the frictions in the equity market. An entrepreneur can issue at most $\theta_{t} i_{t}$ of equity against the new capital she accumulates (the counterpart to these claims is the workers, who cannot invest directly in capital but can buy equity claims in the financial market).

Besides, the entrepreneur can sell at most a fraction $\phi \in[0,1]$ of existing capital in the market. We interpret these financial frictions as representing the "skin in the game" outside investors require from inside equity holders to induce the former to fulfill their contractual

obligations to the latter. These constraints introduce a lower bound to the entrepreneur's capital holdings:

$$
s_{t+1}^{e} \geq\left(1-\theta_{t}\right) i_{t}+(1-\phi)\left(1-\delta\left(u_{t}\right)\right) s_{t}
$$

While $\theta_{t}$ is time-varying, $\phi$ is constant. This distinction captures the idea that there are more fluctuations in the conditions surrounding new investment than in reselling existing capital. Sometimes the new investment is much harder to evaluate and monitor than already existing capital. For example, this can occur when most investment in the economy is related to the arrival of a new general-purpose technology, and outside investors know little about it (or, simply, they know less than insiders). On other occasions, new investment is not harder to evaluate than already existing capital. In our previous example, this can occur when most 
investment in the economy is adding to a mature general-purpose technology. In the former case, $\theta_{t}$ is low (the entrepreneur can issue little outside equity against hard-to-evaluate new projects). In the latter case, $\theta_{t}$ is high (the entrepreneur can issue more outside equity). ${ }^{16}$ See Jurado et al. (2015) for a measurement of how uncertainty regarding financial markets fluctuates in the data and for its possible interpretations.

More concretely, we assume that the salable part of investment, $\theta_{t}$, follows an $\operatorname{AR}(1)$ process:

$$
\theta_{t}=\left(1-\rho_{\theta}\right) \theta+\rho_{\theta} \theta_{t-1}+e^{\sigma_{\theta, t}} \epsilon_{\theta, t}, \text { where } \epsilon_{\theta, t} \sim \mathcal{N}(0,1),
$$

with reflecting barriers at $[0,1]$, mean $\theta$. Again, given our calibration and quantitative exercises, the numerical consequences of the reflecting barriers for $\theta_{t}$ are minor for the ideas in this paper.

The volatility $\sigma_{\theta, t}$ of this process is, itself, another $\operatorname{AR}(1)$ process:

$$
\sigma_{\theta, t}=\left(1-\rho_{\sigma_{\theta}}\right) \sigma_{\theta}+\rho_{\sigma_{\theta}} \sigma_{\theta, t-1}+\left(1-\rho_{\sigma_{\theta}}^{2}\right)^{1 / 2} v_{\theta} u_{\theta, t}, \text { where } u_{\theta, t} \sim \mathcal{N}(0,1)
$$

This financial friction volatility will be the second source of uncertainty shocks in our model and we will call it the "financial friction" uncertainty shock.

Financial frictions create an equivalent lower bound to workers' capital holding:

$$
s_{t+1}^{w} \geq(1-\phi)\left(1-\delta\left(u_{t}\right)\right) s_{t}
$$

but we omit it because this friction does not bind in equilibrium. Since workers are net buyers of equities in the equilibrium we are interested in, we have that $s_{t+1}^{w}>\left(1-\delta\left(u_{t}\right)\right) s_{t}$ always holds and, thus, the constraint (14) is automatically satisfied.

Finally, there are non-negativity constraints for $i_{t}, l_{t}, c_{t}^{e}, c_{t}^{w}$, and $s_{t+1}^{w}$, but we ignore these as well because they do not bind either along the equilibrium path.

\subsection{The problem of the head of the household}

The head of the household chooses directives for its members to maximize the household's total utility:

$$
\mathbb{E}_{t} \sum_{t=0}^{\infty} \beta^{t} d_{t}\left\{\pi \frac{\left(c_{t}^{e}\right)^{1-\rho}-1}{1-\rho}+(1-\pi) \frac{\left[c_{t}^{w}\left(1-\ell_{t}\right)^{\eta}\right]^{1-\rho}-1}{1-\rho}\right\}
$$

\footnotetext{
${ }^{16} \mathrm{An}$ alternative interpretation is that some technologies are harder for outsiders to monitor (i.e., IT) than others (i.e., manufacturing). When new investment is skewed toward the IT sector, $\theta_{t}$ is low. When new investment is skewed toward the manufacturing sector, $\theta_{t}$ is high.
} 
subject to the budget constraints (9) and (10) and the financial constraints (11) and (12). Here, $\beta \in(0,1)$ is the discount factor, $\rho$ is the parameter controlling the elasticity of intertemporal substitution, $\eta$ is the parameter controlling the labor supply of workers, and $d_{t}$ is a preference shock shifter.

This preference shock shifter is a stand-in for fluctuations in tastes, demographics, and fiscal policy, among others, that we do not model explicitly. We will impose the conventional normalization $\bar{d}=1$ and assume that it changes as an $\operatorname{AR}(1)$ process:

$$
d_{t}=\left(1-\rho_{d}\right) \bar{d}+\rho_{d} d_{t-1}+e^{\sigma_{d, t}} \epsilon_{d, t}, \text { where } \epsilon_{d, t} \sim \mathcal{N}(0,1)
$$

Through the variable $\sigma_{d, t}$, equation (16) introduces the third and final source of timevarying volatility in our model: a "demand-side" shock. As we did before, we will assume that the evolution of $\sigma_{d, t}$ also obeys an $\operatorname{AR}(1)$ process:

$$
\sigma_{d, t}=\left(1-\rho_{\sigma_{d}}\right) \sigma_{d}+\rho_{\sigma_{d}} \sigma_{d, t-1}+\left(1-\rho_{\sigma_{d}}^{2}\right)^{1 / 2} v_{d} u_{d, t}, \text { where } u_{d, t} \sim \mathcal{N}(0,1)
$$

The structure of this equation and the parameters follow the same interpretation as in equations (8) and (13). We can interpret $u_{d, t}$ as a "real-rigidity" financial friction uncertainty shock.

\subsection{Inspecting the problem of the household}

To understand the problem of the household better, we can manipulate the different constraints faced by its head. First, we can multiply equation (9) by $\pi$ and equation (10) by $(1-\pi)$, add them, and use equation (11) to aggregate equity holdings and obtain:

$$
\pi c_{t}^{e}+(1-\pi) c_{t}^{w}+q_{t} s_{t+1}=r_{t} u_{t} s_{t}+q_{t}\left(1-\delta\left(u_{t}\right)\right) s_{t}+(1-\pi) w_{t} \ell_{t}+\pi\left(q_{t}-1\right) i_{t} .
$$

Equation (18) is a standard budget constraint at the household level except that the depreciation rate is a function of utilization, $u_{t}$, and, more importantly, because we have the very last term on the right-hand side, $\pi\left(q_{t}-1\right) i_{t}$. Let us spend some time analyzing this term.

If $q_{t}=1$, we have $\pi\left(q_{t}-1\right) i_{t}=0$ and we revert to a standard budget constraint. If $q_{t}>1$, i.e., if the price of equity is above the cost of the final goods required to produce one extra unit of capital, $i_{t}$ relaxes the budget constraint. In other words, the household can make a profit out of investment: the household takes one unit of the final good and obtains one unit of capital with a valuation above one. 
But, because funding is limited by financial frictions, there is a limit to how much the household can benefit from this scheme. Specifically, substituting equation (9) into equation (12), we find the upper bound on $i_{t}$ :

$$
\left(1-\theta_{t} q_{t}\right) i_{t} \leq r_{t} u_{t} s_{t}+\phi q_{t}\left(1-\delta\left(u_{t}\right)\right) s_{t}-c_{t}^{e}
$$

The left-hand side of equation (19) is the minimum amount entrepreneurs have to self-finance to conduct investment $i_{t}$. This amount is smaller than $i_{t}$, the quantity of final good invested, because entrepreneurs can issue $\theta_{t} i_{t}$ of outside equity against the new capital. The righthand side of equation (19) is the maximum liquidity available to entrepreneurs, equal to their equity income, $r_{t} u_{t} s_{t}$, plus the value of the equity that can be sold to outside investors after depreciation, $\phi q_{t}\left(1-\delta\left(u_{t}\right)\right) s_{t}$, minus their consumption, $c_{t}^{e}$. We can think of equation (19) as the feasibility constraint for investment.

We can draw three implications from equations (18) and (19). First, when $q_{t}=1$, the term with $i_{t}$ disappears from the household budget constraint (18) and any level of $i_{t}$ satisfying equation (19) can be optimal. In equilibrium, $i_{t}$ will be determined through the choice of $s_{t+1}$. Intuitively, investment and equity purchases are perfect substitutes because, when $q_{t}=1$, the price of existing capital is identical to the marginal costs of creating new capital. In this case, the inequality constraint (19) does not bind in general.

The second implication is that, if $q_{t}>1$, the inequality constraint (19) must bind at the optimum. If not, the household could increase $i_{t}$ by $\varepsilon>0$ without violating equation (19) and make an extra profit. This increase would loosen the household budget constraint, allowing the household to raise utility by purchasing an additional quantity of the final good for consumption. In other words, if the household can make money from investment, it should utilize this opportunity up to the limit.

Finally, the third implication is that the capital price $q_{t}$ must be strictly less than the inverse of $\theta_{t}$ in equilibrium. If not, we would have that $\left(1-\theta_{t} q_{t}\right) \leq 0$ and the inequality constraint (19) would hold for an arbitrarily large positive $i_{t}$. Because $q_{t}>1$ also holds in this case, the household could relax the budget constraint (18), which would violate market clearing. Intuitively, if $q_{t}$ is not strictly less than the inverse of $\theta_{t}$, entrepreneurs could fully finance the costs of investment by issuing outside equity, and they would be able to engage in an unlimited amount of arbitrage.

As in Shi (2015), we will restrict our attention to the most interesting case in which the equilibrium price of capital always exceeds one. Then, the second implication above gives us that the inequality constraint (19) always binds and the third implication that $1<q_{t}<1 / \theta_{t}$. In this situation, we can combine equations (18) and (19) to obtain a modified household 
budget constraint:

$$
\begin{aligned}
\pi c_{t}^{e}+(1-\pi) c_{t}^{w}+q_{t} s_{t+1} & =r_{t} u_{t} s_{t}+q_{t}\left(1-\delta\left(u_{t}\right)\right) s_{t}+(1-\pi) w_{t} \ell_{t} \\
& +\pi \frac{q_{t}-1}{1-\theta_{t} q_{t}}\left(r_{t} u_{t} s_{t}+\phi q_{t}\left(1-\delta\left(u_{t}\right)\right) s_{t}-c_{t}^{e}\right)
\end{aligned}
$$

The last term of the right-hand side in the previous equation is crucial. It is a product of three components: i) the fraction of entrepreneurs $\pi$; ii) the liquidity held by entrepreneurs after consumption, $\left(r_{t} s_{t}+\phi_{t} q_{t}\left(1-\delta\left(u_{t}\right)\right) s_{t}-c_{t}^{e}\right)$; and iii) the liquidity services:

$$
\lambda_{t}=\frac{q_{t}-1}{1-\theta_{t} q_{t}}
$$

implied by the financial frictions. Since $1<q_{t}<1 / \theta_{t}$, these liquidity services, $\lambda_{t}$, are positive. An entrepreneur can convert one unit of liquidity into $1 /\left(1-\theta_{t} q_{t}\right)$ units of capital by leveraged investment, each of which is worth $q_{t}$ in the market. Hence, $\lambda_{t}$ is the price of this liquidity for the household head.

\subsection{Optimality conditions}

Once we have derived our modified household budget constraint (20), we can find the optimality conditions of the household head for $\ell_{t}, c_{t}^{e}, c_{t}^{w}, s_{t+1}$, and $u_{t}$ by maximizing the utility function (15) subject to equation (20).

The optimality condition for labor supply $\ell_{t}$ is:

$$
\eta \frac{c_{t}^{w}}{1-\ell_{t}}=w_{t}
$$

This condition is standard: the household head equates the marginal rate of substitution of leisure for consumption to wages. Importantly, since the members of the household who become workers are free from the liquidity concern, there is no wedge between the marginal rate of substitution of leisure for consumption and wage. This result does not imply, however, that financial frictions do not have consequences for labor supply. Both $c_{t}^{w}$ and $w_{t}$ are different from what they would otherwise be because of investment changes along the equilibrium path due to those frictions.

The optimality condition for the intra-household consumption allocation $\left(c_{t}^{e}\right.$ vs. $\left.c_{t}^{w}\right)$ is:

$$
\left(c_{t}^{e}\right)^{-\rho}=\left(1+\lambda_{t}\right)\left(c_{t}^{w}\right)^{-\rho}\left(1-\ell_{t}\right)^{\eta(1-\rho)} .
$$

This optimality condition shows the existence of a wedge between the entrepreneur's marginal 
utility from consumption and the worker's, $1+\lambda_{t}>0$. Specifically, the entrepreneur's marginal utility is larger than the worker's because liquidity services, $\lambda_{t}$, are positive. The reason comes from the budget constraint (20). The entrepreneur's consumption increases the uses in the left-hand side of the equation and reduces the resources on the right-hand side. In comparison, the worker's consumption increases the uses on the left-hand side while leaving resources untouched. In other words: the household head understands that the entrepreneur's consumption has a higher opportunity cost than the worker's. Every extra amount of resources that the household head allocates to the consumption of entrepreneurs reduces the liquidity of the latter and, with it, the additional profits that investment delivers under financial frictions.

The Euler equation for investment (or equivalently, for equity claims and, hence, intertemporal allocations) is:

$$
\begin{aligned}
q_{t}=\mathbb{E}_{t}\{\beta & \left(\frac{d_{t+1}}{d_{t}}\right)\left(\frac{c_{t+1}^{w}}{c_{t}^{w}}\right)^{-\rho}\left(\frac{1-\ell_{t+1}}{1-\ell_{t}}\right)^{\eta(1-\rho)} \\
& \left.*\left(r_{t+1} u_{t+1}+\left(1-\delta\left(u_{t}\right)\right) q_{t+1}+\pi \lambda_{t+1}\left(r_{t+1} u_{t+1}+q_{t+1} \phi\left(1-\delta\left(u_{t}\right)\right)\right)\right)\right\} .
\end{aligned}
$$

This condition determines the price of capital $q_{t}$. Notice that the worker's marginal utilities are in the stochastic discount factor because workers are the marginal investors purchasing the outside equity. We also have the ratio of $\left(\frac{d_{t+1}}{d_{t}}\right)$ of preference shifters that tell the household head how much to discount the present relative to the future with respect to the average discount factor $\beta$. As we discussed before, the term in the right-hand side $\left(1-\delta\left(u_{t}\right)\right) q_{t+1}+\pi \lambda_{t+1}\left(r_{t+1} u_{t+1}+q_{t+1} \phi\left(1-\delta\left(u_{t}\right)\right)\right)$ summarizes the benefits of holding equity, among which the last term is for providing liquidity to entrepreneurs.

The last optimality condition is with respect to the utilization rate of capital. The condition $r_{t}=q_{t} \delta^{\prime}\left(u_{t}\right)$ equates the marginal return of using the capital at a higher rate with the marginal depreciation it triggers.

The competitive equilibrium for this economy is standard, and, in the interest of space, we skip its explicit definition. It is worthwhile, however, to recall that the market-clearing conditions for final goods, factor services, and equity are:

$$
\begin{gathered}
\pi c_{t}^{e}+(1-\pi) c_{t}^{w}+\pi i_{t}=A_{t}\left(k_{t}^{D}\right)^{\alpha}\left(l_{t}\right)^{1-\alpha}, \\
l_{t}=(1-\pi) \ell_{t}, \\
k_{t}^{D}=u_{t} k_{t},
\end{gathered}
$$


and

$$
k_{t}=s_{t}
$$

respectively, for all $t$.

Finally, the capital accumulation rule relies on the investment by entrepreneurs and the decisions on the utilization rate of capital:

$$
k_{t+1}=(1-\delta(u)) k_{t}+\pi i_{t}
$$

\section{Computation}

Because our model has no closed-form solution, we solve it numerically. The solution method is standard, and it is described in detail in Fernández-Villaverde et al. (2016). We first find the deterministic steady state of the model. ${ }^{17}$ Next, we take a third-order approximation in levels of the system of equations characterizing the equilibrium around such a steady state. ${ }^{18}$ Third, we compute the generalized impulse response functions, GIRFs, of variables of interest to different shocks (for details, see Koop et al., 1996, and Andreasen et al., 2018). In particular, we will report the GIRFs in percentage points from the deterministic steady state, when all the other shocks are at their mean levels.

Three points deserve further discussion. First, our choice of a perturbation solution. Models with uncertainty shocks are highly dimensional. In addition to the standard state variables (i.e., capital, preference shocks, productivity levels, etc.), we also need to keep track of the volatility levels, which become additional state variables when they are time-varying. In our case, we have seven state variables: the three level shocks, the three uncertainty shocks, and capital. Thus, dynamic programming and projection methods, both of which suffer from an acute curse of dimensionality, can be hard to implement. Perturbation, in comparison, can handle large state spaces without a problem and often delivers outstanding accuracy even far away from the perturbation point (Aruoba et al., 2006, and Caldara et al.,

\footnotetext{
${ }^{17}$ The deterministic steady state is the fixed point of the equilibrium conditions of the model when the volatility of all shocks has been driven to zero. In contrast, the stochastic steady state is the fixed point of the equilibrium conditions of the model when the realization of all shocks in the period is zero. These two steady states will be different in general because of precautionary behavior. Also, even when the deterministic steady state is unique, we can encounter multiple stochastic steady states. See Fernández-Villaverde et al. (2019a) for an example of such a situation.

${ }^{18} \mathrm{~A}$ technical note is relevant here. It is most advisable to perform the perturbation around the deterministic steady state, even in the presence of uncertainty shocks that may move the stochastic steady state substantially. First, all the theoretical results involving the consistency of a perturbation with respect to the exact but unknown solution depend on such a perturbation being taken around the deterministic steady state. Second, we know how to evaluate all the relevant derivatives only at the deterministic steady state. Otherwise, we need to engage in an iterative procedure that quickly goes astray.
} 
2012).

A promising alternative to perturbation for solving this class of models is Taylor projection. As described in Fernández-Villaverde and Levintal (2018), Taylor projection is a hybrid of perturbation and projection methods that yields excellent accuracy even when the shocks are large, the solution of the model presents high curvature, and the state variables are far away from the deterministic steady state. Indeed, an advantage of Taylor projection is that the series expansion can be undertaken in points different at the deterministic steady state and make it depending on values of the state variables. Fernández-Villaverde and Levintal (2018) show how a Taylor projection can handle models with time-varying rare disasters, like those described in Section 3, quickly and efficiently.

An even more radical departure with respect to existing solution methods is the use of machine learning algorithms, such as neural networks and deep learning. Thanks to a smart choice of basis functions and a simulation approach to the selection of coefficients weighting these basis functions, these algorithms can break the curse of dimensionality and deal even with the strongest non-linearities. Therefore, they are particularly promising for this class of problems. See Fernández-Villaverde et al. (2019a) for details.

Second, we perform a third-order perturbation because we are interested in tracing the effects of an uncertainty shock. As we discussed in Section 3, a first-order perturbation is certainty equivalent and, therefore, not useful to study uncertainty shocks. A second-order perturbation incorporates the effects of uncertainty shocks, but only in terms involving cross-products of level and volatility shocks. It is in the third-order perturbation that we find terms in the solution that only involve uncertainty shocks and, hence, we can compute their GIRFs (which is, intuitively, a partial derivative over time). Fernández-Villaverde et al. (2015b) present a formal proof of this claim. ${ }^{19}$

Sometimes, and for accuracy purposes, one may need to go to higher perturbation orders, but for our model, in this paper terms of order higher than three are of minor quantitative importance. See, nevertheless, Levintal (2017) for examples and advice on how to implement such higher-order perturbations.

Third, we compute GIRFs because, once one is dealing with a non-linear solution, the responses of variables of interest to shocks are state-dependent: they are a function of the size and sign of the shock, and the point in the state space where the economy is at the arrival of the shock. In comparison, in a linear model, the regular impulse response functions are

\footnotetext{
${ }^{19}$ There is a caveat to remember. Except in a few particular cases, we do not have a proof that the decision rules that we solve for are differentiable with respect to the uncertainty shocks. This is a problem, however, for higher-order perturbation methods in general, regardless of whether they deal with uncertainty shocks. However, note that perturbation methods only require the existence of partial derivatives, not total differentiability.
} 
independent of the point in the state space where the economy is, and their shape is just a scale up or down of the size and sign of the shock. ${ }^{20}$

\section{Calibration}

Our next step is to take the model to the data. To do so, the literature has opted for one of two approaches. The first route is to estimate the model formally using econometric tools. When the model is solved using a third-order perturbation, this can be easily done by building the moments of the ergodic distributions of variables of interest and minimizing a quadratic distance to the analogous moments in the data. This point is often crucial because, when the model is solved non-linearly, the first moments of the ergodic distribution and the deterministic steady state can be far away from each other due to precautionary behavior (although, in our current model, this concern is not of great importance). Andreasen et al. (2018) show how this moment matching can be done in a few seconds by providing analytic formulae for all the relevant expressions.

Alternatively, we can use a particle filter to evaluate the likelihood function implied by the model and, then, rely on a Markov chain Monte Carlo to either sample from the posterior (if we specify a prior and adopt the Bayesian approach) or search for a maximum (if we stay within a frequentist paradigm). Fernández-Villaverde (2010) and Fernández-Villaverde et al. (2016) explain these ideas in detail. ${ }^{21}$ One advantage of sequential Monte Carlos (such as the particle filters) is that they are particularly amenable to massive parallelization, an enormous advantage in an era of graphics processing unit (GPUs), field-programmable gate arrays (FPGAs), and cloud services. See Fernández-Villaverde and Valencia (2018) for a tutorial on how to do so.

The second route is to implement a standard calibration. Since the goal of this paper is to illustrate how uncertainty shocks affect aggregate fluctuations, we follow this latter route: it is simpler than a formal structural estimation, and it saves us plenty of space that we can

\footnotetext{
${ }^{20}$ To see this, note that the linear approximation to the log-deviation of output, $\widehat{y_{t}}$, in a standard real business cycle model, is a linear function of the log-deviation of capital, $\widehat{k_{t}}$, productivity at the start of the period, $z_{t-1}$, and the productivity shock, $\varepsilon_{t}$ :

$$
\widehat{y_{t}}=a_{1} \widehat{k_{t}}+a_{2} z_{t-1}+a_{3} \varepsilon_{t} .
$$

Thus, the effect of $\varepsilon_{t}$ on $\widehat{y_{t}}$ is through $a_{3}$, regardless of the values of $\widehat{k_{t}}$ and $z_{t-1}$. In addition, the effect is a linear function of $\varepsilon_{t}$. In a higher-order perturbation, we encounter terms of the form $a_{4} \widehat{k_{t}} \varepsilon_{t}$ that induce state-dependence and terms of the form $a_{5} \varepsilon_{t}^{2}$ that make the shape of the response depend on the size and sign of the shock.

${ }^{21}$ See also Guerrón-Quintana (2010) for advice in the selection of observables to feed into the likelihood function.
} 
put to good use in providing further intuition.

To match data from national income and product accounts, we pick a quarter of a year as our period. Many of the parameter value choices are standard in the literature. For instance, we set the discount factor to $\beta=0.994$ and the parameter controlling risk aversion to $\rho=2$. Similarly, we set the utilization rate to 1 in the steady state and the elasticity of $\delta(\cdot)^{\prime}$ to 0.33 as in Comín and Gertler (2006).

We follow Shi (2015) in setting the fraction of investors to $\pi=0.06$ and the capital share to $\alpha=0.36$, and in assuming that the fraction of new equity $\theta$ is equal to the steady-state resealability $\phi$.

We move now to our explicit targets. We calibrate three parameters - the steady-state resealability, $\phi$, the curvature in leisure in the utility function, $\eta$, and the capital depreciation rate $\delta$ - using three observations from the U.S. economy commonly employed in business cycle research: the aggregate hours of work in the deterministic steady state $(1 / 3)$, the ratio of capital to annual output in the deterministic steady state (3.30), and the ratio of annual investment to capital in the steady state $(0.075)$.

Our last task is to determine the parameters of the six shocks. We start with the persistence of the level shocks. A conventional value for the persistence of technology, $\rho_{A}$, is 0.95 (Cooley and Prescott, 1995). For symmetry, we pick the same persistence for preferences, $\rho_{d}$, and the financial friction, $\rho_{\theta}$. We deem these parameter values as reasonable given the empirical evidence from Bloom et al. (2018) and Fernández-Villaverde et al. (2015a). All the persistences of the uncertainty shocks are set to 0.75 , roughly around the mean of the persistences estimated by Fernández-Villaverde et al. (2015a).

Next, we need the means of uncertainty shocks. As a target for the mean of the demand uncertainty, $\sigma_{d}$, we use the estimate of $\log (0.13)$ in Fernández-Villaverde et al. (2015a). For the mean of the technology uncertainty, $\sigma_{A}$, we use $\log (0.007)$ from Cooley and Prescott (1995). For the mean of the financial friction uncertainty, $\sigma_{\theta}$, we use $\log (0.033)$ from GuerrónQuintana and Jinnai (2019a).

Finally, we select the scale of the uncertainty shocks (i.e., the parameters $v_{A}, v_{d}$, and $\left.v_{\theta}\right)$ to yield that a one-standard-deviation positive innovation to the uncertainty shocks doubles its level. The literature on uncertainty shocks typically studies relatively large shocks, such as two- or three-standard-deviation-innovations (see Bloom, 2009, Bloom, 2014, and Fernández-Villaverde et al., 2015a, among many others). The reason is that these are the range of changes in uncertainty associated with events such as geopolitical crises, financial turbulence, large political upheavals, and similar developments. This area of research does not seek to replace regular level shocks, such as productivity or demand innovations, but to complement them by studying the consequences of large events. As such, the literature 
acknowledges that much of the variation in aggregate variables in average quarters will be driven by level shocks, not uncertainty shocks.

Thus, all the GIRFs to uncertainty shocks reported in Section 8 plot the evolution of the aggregate variables after a one-standard-deviation positive innovation to the corresponding uncertainty shock. Given the aims of this paper, such normalization is the best choice to illustrate how uncertainty shocks operate. In a more fully fledged model, the scale can be picked, for instance, to match some properties of the estimated volatilities from the data. Table 2 summarizes our calibration (and where u.s. stands for uncertainty shock).

Table 2: Parameters and Calibration Targets

\begin{tabular}{lcc}
\hline Parameter & value & Calibration Target \\
\hline$\beta:$ discount factor & 0.994 & Exogenously chosen \\
$\rho:$ relative risk aversion & 2 & Exogenously chosen \\
$\pi:$ fraction of entrepreneurs & 0.06 & Annual fraction of investing firms $=0.24$ \\
$\eta:$ curvature in leisure utility & 1.525 & Hours of work $=1 / 3$ \\
$\alpha:$ capital share & 0.36 & Labor income share $(1-\alpha)=0.64$ \\
$\delta_{0}:$ capital depreciation rate & 0.016 & Annual investment/capital $=0.065$ \\
$\delta_{1}:$ slope depreciation function & 0.013 & Pinned down by steady state \\
$\delta_{2}:$ curvature depreciation function & $0.33 \times \delta_{1}$ & Comín and Gertler $(2006)$ \\
$\phi:$ resealability & 0.095 & Capital stock/annual output $=3.30$ \\
$\theta:$ mean fraction of new equity & 0.095 & Set equal to $\phi$ \\
$\rho_{d}:$ persistence of preferences & 0.95 & Exogenously chosen \\
$\rho_{A}:$ persistence of technology & 0.95 & Cooley and Prescott $(1995)$ \\
$\rho_{\theta}:$ persistence of financial friction & 0.95 & Exogenously chosen \\
$\rho_{\sigma_{d}}=\rho_{\sigma_{A}}=\rho_{\sigma_{\theta}}:$ persistence of u.s. & 0.75 & Fernández-Villaverde et al. $(2015 \mathrm{a})$ \\
$\sigma_{d}:$ mean of preference u.s. & $\log (0.13)$ & Fernández-Villaverde et al. $(2015 \mathrm{a})$ \\
$\sigma_{A}:$ mean of technology u.s. & $\log (0.007)$ & Cooley and Prescott $(1995)$ \\
$\sigma_{\theta}:$ mean of financial friction u.s. & $\log (0.007)$ & Cooley and Prescott $(1995)$ \\
\hline \hline
\end{tabular}

\section{Results}

We can now study the effects of the three uncertainty shocks in our model. First, we will analyze the uncertainty shock to preferences, to productivity, and to the financial friction. In the interest of concision, we will not report the GIRFs of level shocks to preferences and productivity (they are, though, rather conventional), but we will include the GIRFs of the level shock to the financial friction. Second, we will study how the propagation of the three uncertainty shocks change as we modify the tightness of the financial friction. 


\subsection{Uncertainty shock to preferences}

Figure 5 displays the GIRFs to an increase in the uncertainty of the preference shifter, our "demand-side" shock, that doubles its standard deviation (center panel, bottom row). That is, upon impact, the volatility of $d_{t}$ goes up to $2 \times \sigma_{d}$ (recall the scaling in our calibration).

We can see in Figure 5 that, after the preference uncertainty shock, output (left panel, top row), investment (right panel, top row), and labor go up (left panel, middle row), while consumption falls (center panel, top row). Higher uncertainty about future preferences means that the household faces a larger probability of an event where marginal utility is very high (remember that the utility function is multiplied by the demand shifter $d_{t}$ ). The household also faces a larger probability of an event where marginal utility is very low, but such an event is of lower concern for the maximization problem because of the concavity of the utility function.

Figure 5: Impact of an increase in uncertainty on preference shock
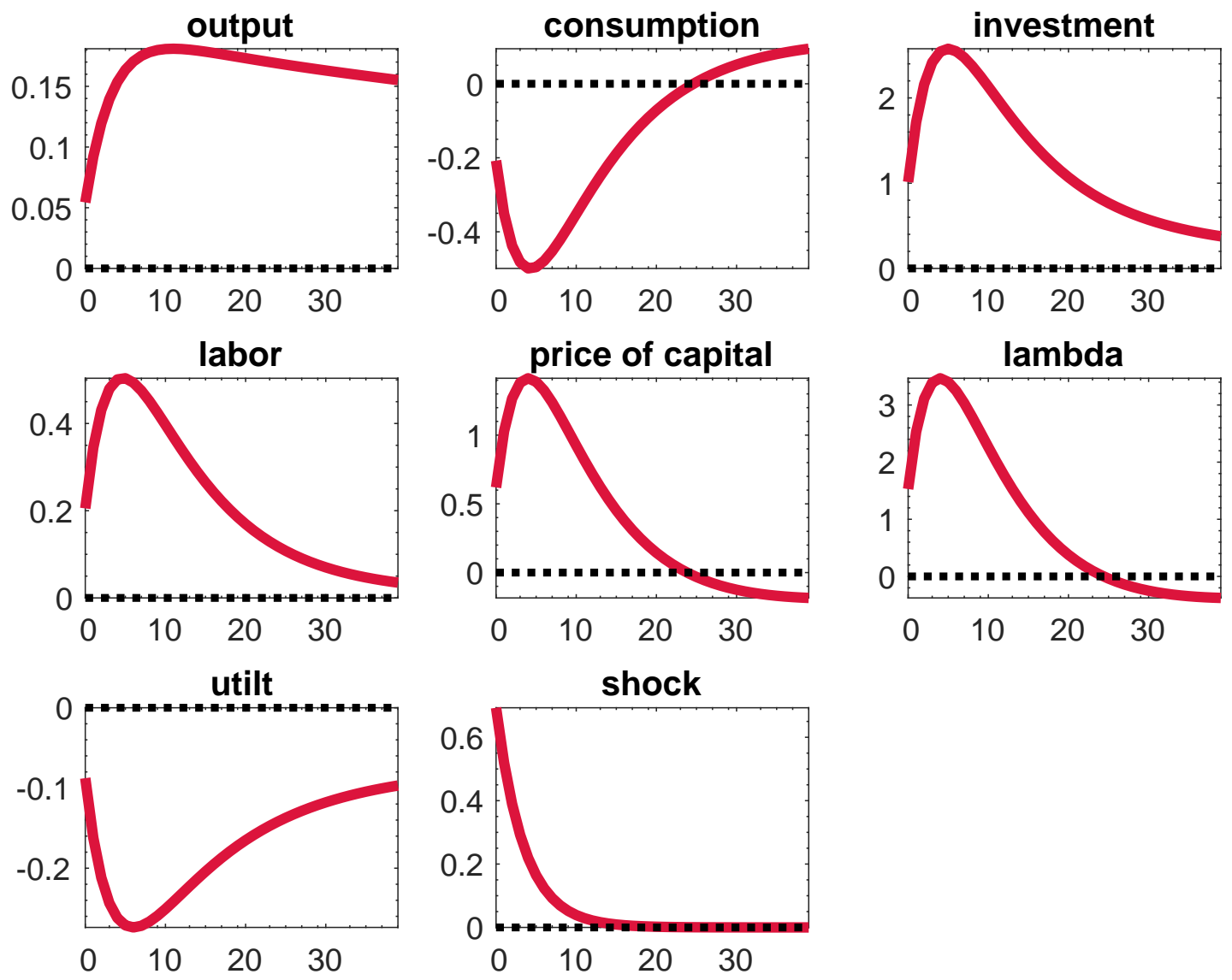

NOTE: Variables correspond to percentage deviations from their steady states.

To limit the effect of these high marginal utility events, the head of the household orders 
an increase in precautionary savings. More concretely, the head of the household instructs its members to consume less, save (i.e., invest) more, and work harder than before. The strong desire to save is more than enough to offset the decline in consumption, resulting in a boom in output. In the absence of nominal rigidities, labor increases to meet the additional production. Additionally, higher savings from workers raise the demand for equity, and hence its price, $q_{t}$ (center panel, middle row). Consequently, the liquidity services $\lambda_{t}$ go up (right panel, middle row).

The shock leads to relatively persistent deviations, with output rising by 20 basis points at around 12 quarters after impact. That is, we can get a clear and prominent expansionary effect of uncertainty shocks, a new result in the literature, where most of the (positive) uncertainty shocks have to deliver contractionary effects. This result is particularly intriguing because it can help us reconcile some observations about the evolution of uncertainty and business cycles. Some uncertainty shocks are contractionary (such as the fiscal volatility shocks in Fernández-Villaverde et al., 2015a, or the shocks in Bloom, 2009), but some might be expansionary. Thus, naive econometric methods that find mild effects of uncertainty variations might be just mixing the effects of these two very different classes of uncertainty shocks.

Also, the model generates hump-shaped GIRFs in output, hours worked, consumption, and investment despite the absence of habit formation and adjustment costs in investment. These GIRFs are a remarkable finding since simulations in Basu and Bundick (2017) show that real business cycle models fail to generate hump-shaped dynamics after a preference uncertainty shock.

Our model triggers those responses because of two forces. Upon impact, demand for new capital rises, which pushes the price of capital up and increases the liquidity services provided by capital. The jump in $q_{t}$ relaxes the financial constraint (19), allowing the household to invest more. This force resembles the valuation mechanism at the center of the model by Kiyotaki and Moore (1997), except that we are dealing with an uncertainty shock, not with a productivity level shock. At the same time, the newly created capital competes with already existing capital in the provision of liquidity, which makes adding more capital unappealing for the household. Eventually, this second force dominates, driving down investment, prices, and liquidity.

Three additional points are salient to understanding Figure 5. First, despite the output boom, the utilization rate goes down (left panel, bottom row): since capital is now more valuable, the household head wants to maintain it for the future (when a bad preference shock might arrive) by reducing depreciation.

Second, the movements in the variables occur even if no fundamental has changed. What 
has changed is the probability of future changes in fundamentals (e.g., the demand shifter). Thus, a researcher who does not appreciate the importance of uncertainty shocks might find herself puzzled by the co-movement of aggregate variables displayed by Figure 5: variables move in different directions and, yet, no obvious (traditional) shock has arrived.

Third, even if output goes up, the period utility at impact is lower: the household is working more and consuming less. With uncertainty shocks, we must be careful in reading positive welfare implications from output booms.

\subsection{Uncertainty shock to productivity}

Figure 6 shows the dynamics of macroeconomic variables following an increase in the volatility of the productivity shock, $\sigma_{A, t}$, our "supply-side shock." As we did with the preference shock, we look at the case when the volatility of productivity doubles after the increase in uncertainty. The ordering of the panels is the same as in Figure 5, except that the uncertainty shock (center panel, bottom row) is now the productivity one, instead of the uncertainty shock to preferences.

We see in Figure 6 that, after the arrival of the uncertainty shock, output, investment, and labor go up, while consumption drops for a few quarters and, then, soon recovers. Similarly, the price of capital and the liquidity services go up. The utilization rate of capital, in contrast to Figure 5, increases.

At first sight, Figures 5 and 6 look very similar, including the expansionary effect of positive uncertainty shocks and the presence of humps in the variables of interest. However, the divergent evolution of the utilization rate of capital (lower after a preference volatility

shock, bigger after a productivity volatility shock) reveals that very different mechanisms are at work.

Precautionary behavior is behind Figure 5. In comparison, the Oi-Hartman-Abel effect is behind Figure 6 (recall Subsection 3.2). While the production function of the representative firm in our economy is constant-returns-to-scale, the presence of financial frictions reduces the elasticity of capital supply, with $q$ departing from 1 (which would always be the case without those financial frictions). This departure amounts, in practice, to a behavior of the firm that closely resembles the case where the production function has decreasing-returnsto-scale and triggers the Oi-Hartman-Abel effect.

The head of the household responds to this Oi-Hartman-Abel effect by asking the household members to work harder, invest more, and utilize the capital more. The utilization rate goes up because the Oi-Hartman-Abel effect tells the household to increase the capital services that the representative firm employs, which in the short run can be achieved through 
higher utilization of capital, even if at the cost of higher depreciation. Investment goes up so much that consumption goes down at impact. In other words, the household wants to be ready for the situation where a particularly good productivity shock arrives (the uncertainty shock makes it more likely than before).

Figure 6: Impact of an increase in uncertainty on productivity shock
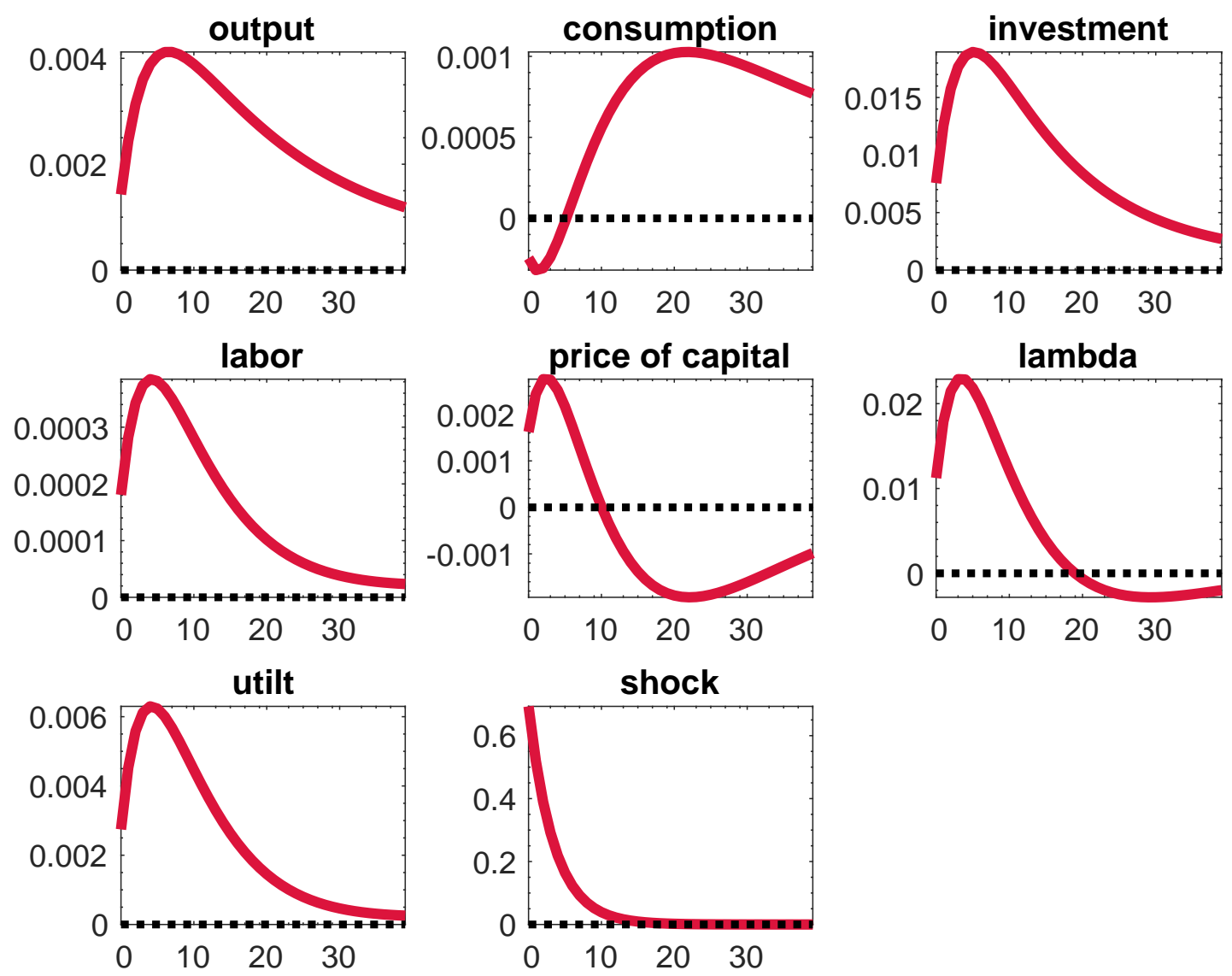

NOTE: Variables correspond to percentage deviations from their steady states.

Also, accumulating extra capital has the additional advantage for the household of providing extra insurance if the production shock is very negative (capital can be transformed back into consumption or used to produce more of the final good for consumption). Note, however, that these effects are quantitatively smaller than the ones in our previous uncertainty preference shock.

\subsection{Level shock to the financial friction}

Before we can study the consequences of an uncertainty shock to the financial friction, we need to spend some time studying the level effect of a change in $\theta_{t}$, since some of the 
impulse responses are not obvious (compare, for instance, our model with the regular financial accelerator model of Bernanke et al., 1999).

Figure 7 reports the consequences of a positive one-standard-deviation shock to $\theta_{t}$ (note how, for level shocks, we report a traditional one-standard-deviation GIRF). The ordering of the panels is the same as in Figure 5, except that the center panel, bottom row, reports the level shock to $\theta_{t}$.

Figure 7: Impact of $\theta$
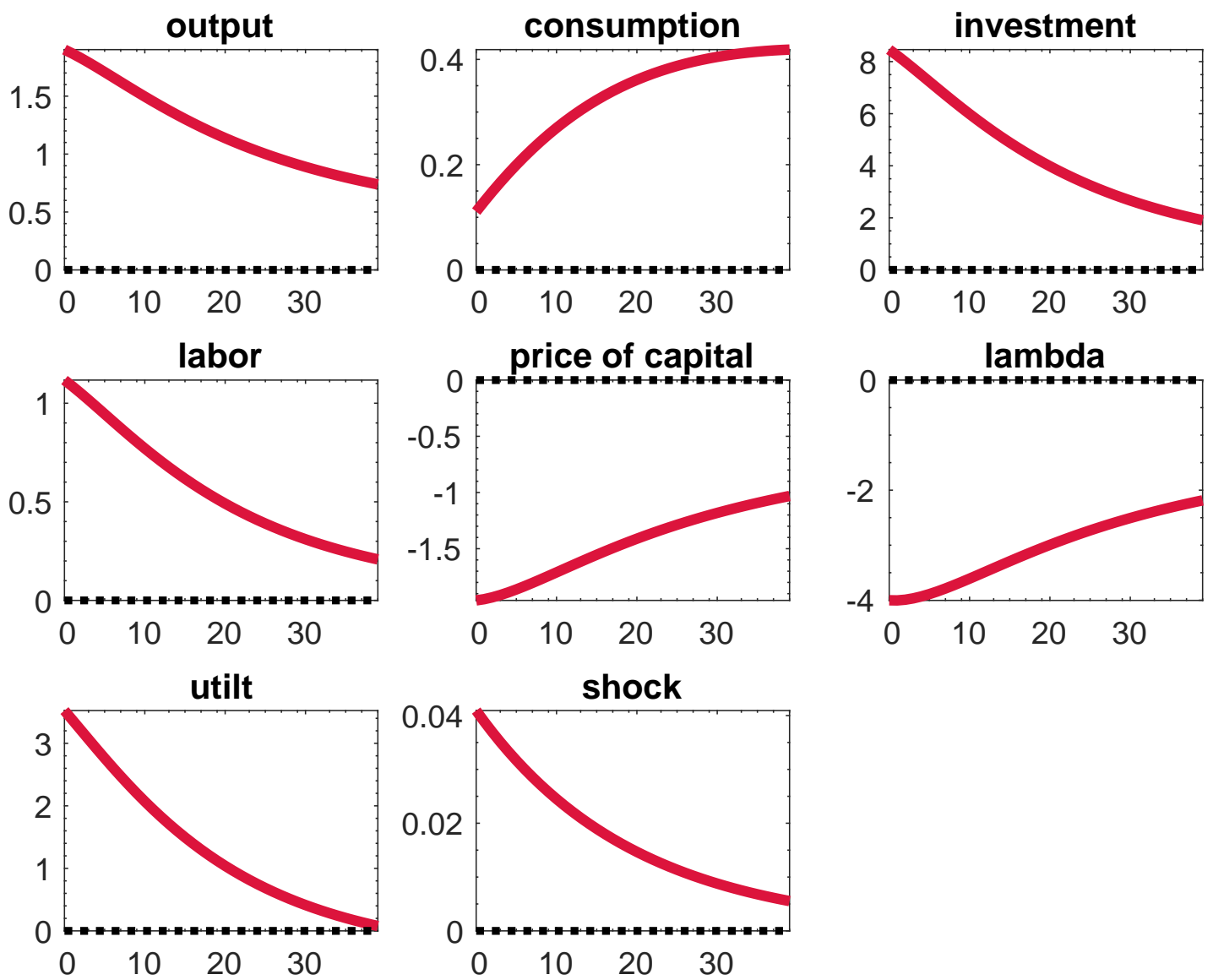

NOTE: Variables correspond to percentage deviations from their steady states.

The increase in $\theta_{t}$ means that entrepreneurs can issue more equity against new capital. There are different possible interpretations for such exogenous changes in the financial markets and their willingness to buy outside equity. For instance, we can have a tightening in the regulation protecting outside investors, or as we mentioned before, the concentration of investment in a general-purpose technology that is easier to monitor.

After $\theta_{t}$ rises, the investment constraint in equation (19) relaxes. This relaxation leads to more investment and, with it, to a lower price of capital. The newly created capital provides 
additional liquidity, and liquidity services fall. The drop in $q_{t}$ makes investment even cheaper, leaving additional resources for the households to consume. Hence, consumption goes up. Firms meet the additional demand by increasing utilization and hiring more labor.

The reduction in $q_{t}$ goes against the standard intuition that an improvement in financial conditions (in this case, easier issuance of outside equity) should lead to a stock market boom. Shi (2015) shows that this counterintuitive result is a general problem of models with financial frictions. ${ }^{22}$ Guerrón-Quintana and Jinnai (2019b) use an endogenous-growth mechanism to restore the dynamics in asset prices after a financial shock.

\subsection{Uncertainty shock to the financial friction}

With this background in place, we can move to discuss the impact of a financial uncertainty shock $u_{\theta, t}$. We report our findings in Figure 8. A financial uncertainty shock makes it more likely that $\theta_{t}$ will increase in the next period by a large amount. Since pledging capital will be easier in the future than today, the household head orders entrepreneurs to postpone investment and increase consumption today.

However, the probability that $\theta_{t}$ goes down significantly in the next period has increased too. Under this scenario, the pledgeability of capital will decline sharply, making investment more expensive. The entrepreneurs do not want to be caught in a situation of not having enough resources to invest because of a tighter financial friction ( $\theta_{t}$ down) and low installed capital (resulting in low $\left.\phi q_{t}\left(1-\delta\left(u_{t}\right)\right) s_{t+1}\right)$. This channel pushes investment up in the current period, because, in such a way, there will be more installed capital to be used as collateral in the next period. We can call this mechanism "precautionary investment." The economic intuition is related, but not equal, to the option value effect of investment under irreversibility (Bernanke, 1983, and Dixit and Pindyck, 1994).

Because of the concavity of the utility function, the second scenario - the large drop in $\theta_{t}-$ is more adverse for the household than the first one. Thus, the head of the household instructs entrepreneurs to increase investment and the utilization of capital, and workers to work longer hours. As in other cases, a higher investment lowers the price of capital and the value of liquidity services. The household, as a response to the lower price of capital, consumes more to smooth marginal utilities over time.

Finally, note that the expansion induced by an uncertainty shock to the financial friction is larger than the effects of the other two uncertainty shocks (notice the scales in the vertical axis of each panel). This quantitative result backs up the conjecture that the relations

\footnotetext{
${ }^{22}$ Similarly, this idea is also behind why models with bubbles can increase investment (Farhi and Tirole, 2012). Anything that increases the value of capital above "fundamentals" leads, in general, to more investment. By giving capital a liquidity service, financial frictions tend to have this implication as well.
} 
Figure 8: Impact of an increase in uncertainty on financial shock
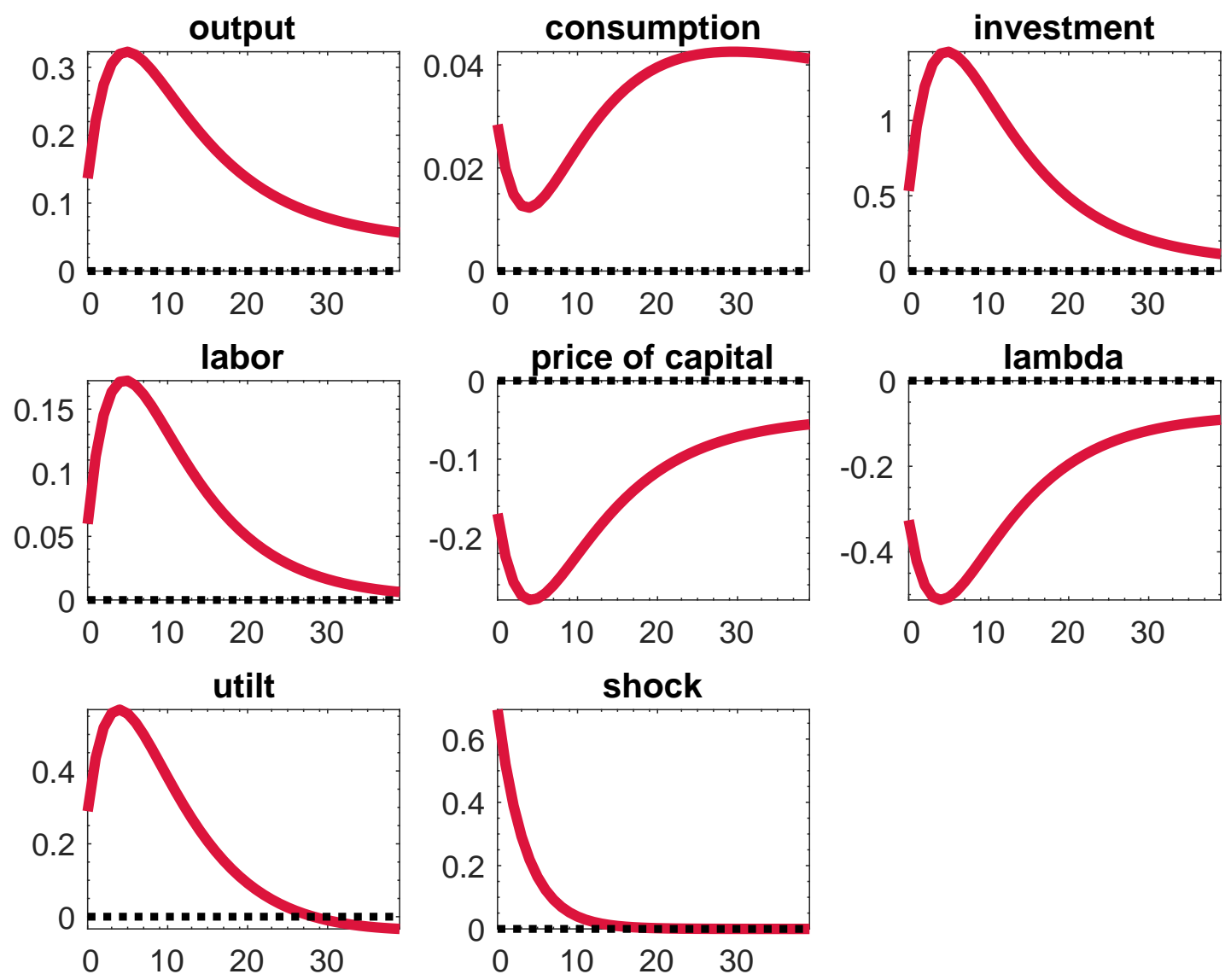

NOTE: Variables correspond to percentage deviations from their steady states.

between financial markets and uncertainty are at the very core of how uncertainty operates in terms of allocations. This point has already beeen highlighted in Fernández-Villaverde et al. (2011) and Arellano et al. (2019), it is implicit in the empirical results in the VAR estimated by Bloom (2009), and it motivates our next experiment.

\subsection{Financial frictions and the propagation of uncertainty shocks}

Given our previous discussion, a natural question is: how important are financial frictions for the propagation of uncertainty shocks, even those that do not come from the financial market?

To gauge this importance, we vary the degree of liquidity in the economy and report our results in Figures 9-11. In each of these figures (again, with the same ordering of variables that we followed in previous figures), we consider two scenarios: our benchmark calibration (red solid line) and looser financial constraints (blue discontinuous line) where 
$\theta=0.20$, i.e., the mean pledgeability is roughly twice as high as in the benchmark calibration and more outside equity can be issued (we keep $\theta$ at the same level as in the benchmark calibration). Because of our calibration strategy, the looser financial constraint implies a higher investment-to-capital ratio.

In the case of uncertainty shocks to preferences (Figure 9), the effect of modifying the financial friction is quite small: output increases slightly more, but consumption, investment, and labor remain roughly unchanged. The liquidity services increase substantially more, but this has a minor impact on allocations.

Figure 9: Role of financial friction in propagation of uncertainty in preferences
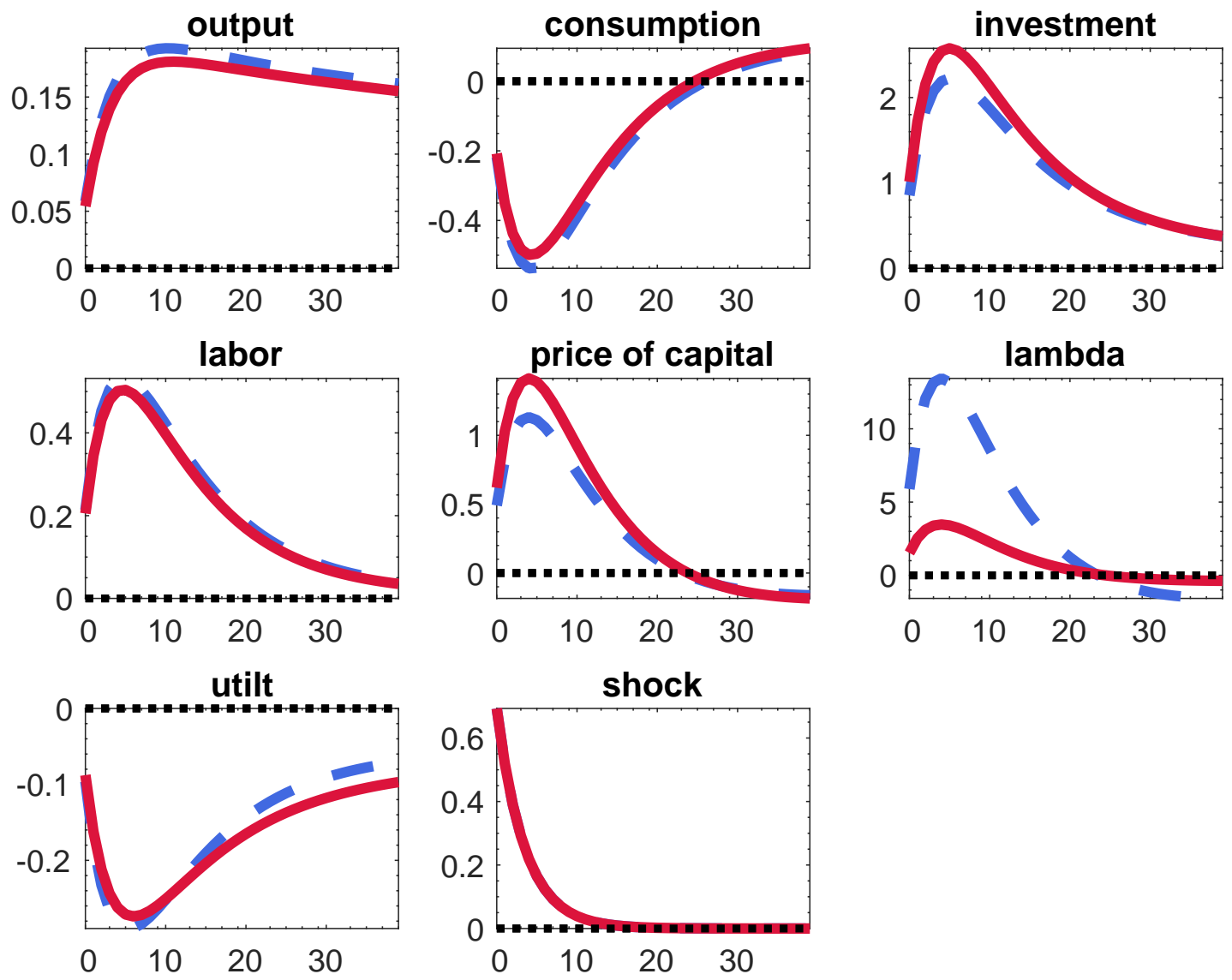

NOTE: Variables correspond to percentage deviations from their steady states.

In contrast, a looser financial constraint has a significant impact on the propagation of the productivity uncertainty shock (Figure 10) and in particular, to the uncertainty shock to the financial friction (Figure 11).

The intuition for the case of the productivity uncertainty shock is straightforward. When the financial friction is looser, the Oi-Hartman-Abel effect is weaker. The head of the house- 
Figure 10: Role of financial friction in propagation of productivity uncertainty
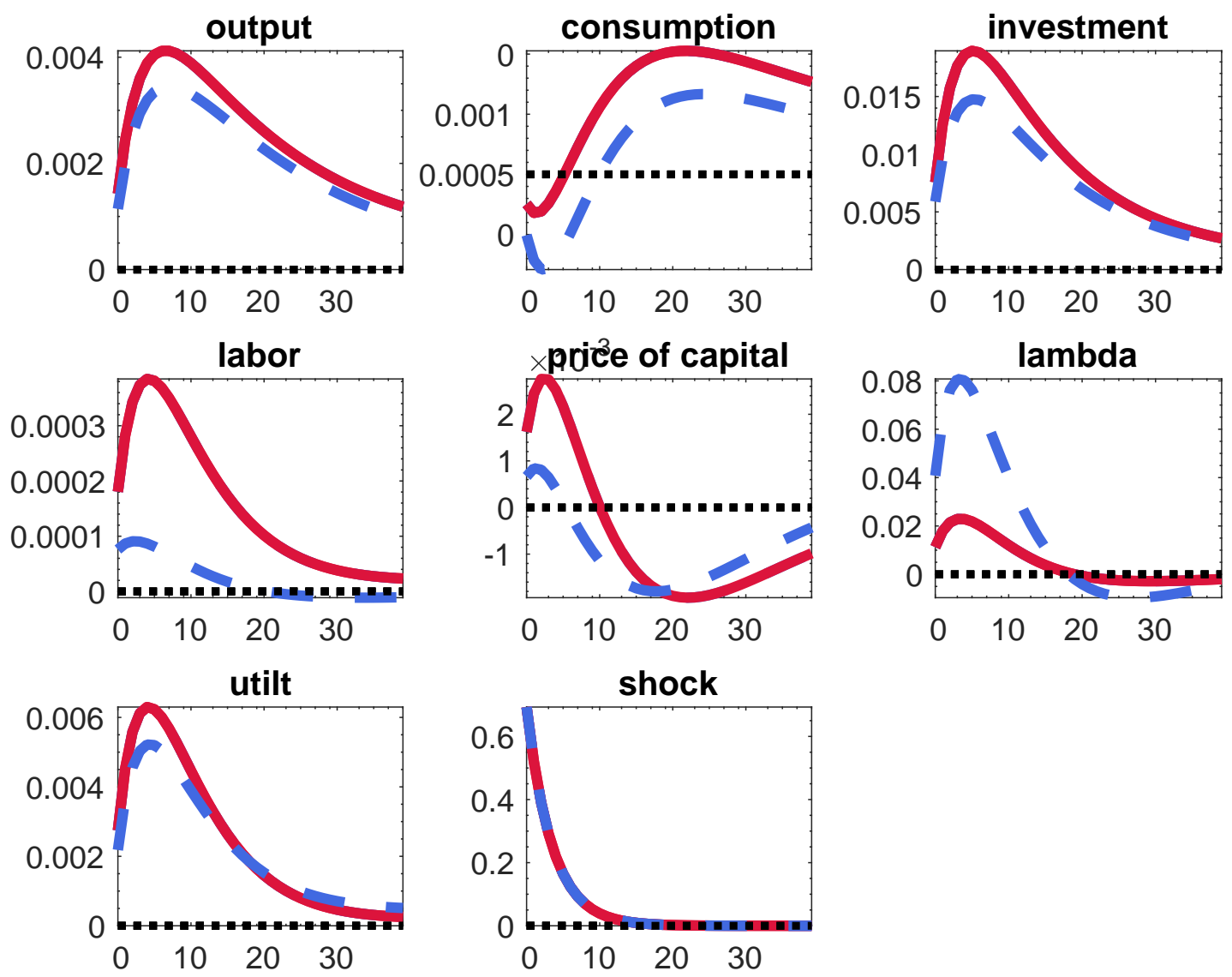

NOTE: Variables correspond to percentage deviations from their steady states.

hold can instruct entrepreneurs to invest more when the good productivity shock arrives, and it does not need to accumulate as much capital in the expectation that such a shock will arrive in the near future and we cannot invest as much as we desire.

The mechanism in the case of the financial friction uncertainty shock is related. If the financial restriction is relaxed, the economy enjoys more liquidity, and entrepreneurs can issue more equity against their new investment when the good shocks arrive. Entrepreneurs are less concerned about a future decline in $\theta$ (because of higher uncertainty today). Hence, they choose to increase investment by a smaller fraction than in the benchmark scenario, and output rises much less.

In summary, our exercise illustrates that financial frictions make uncertainty shocks much more significant. Based on this observation, we close this section with two conjectures for future research. First, in the presence of household heterogeneity, such effects could be even more significant. Second, the reason why many emerging economies have wilder business cy- 
Figure 11: Role of financial friction in propagation of uncertainty in financial shock
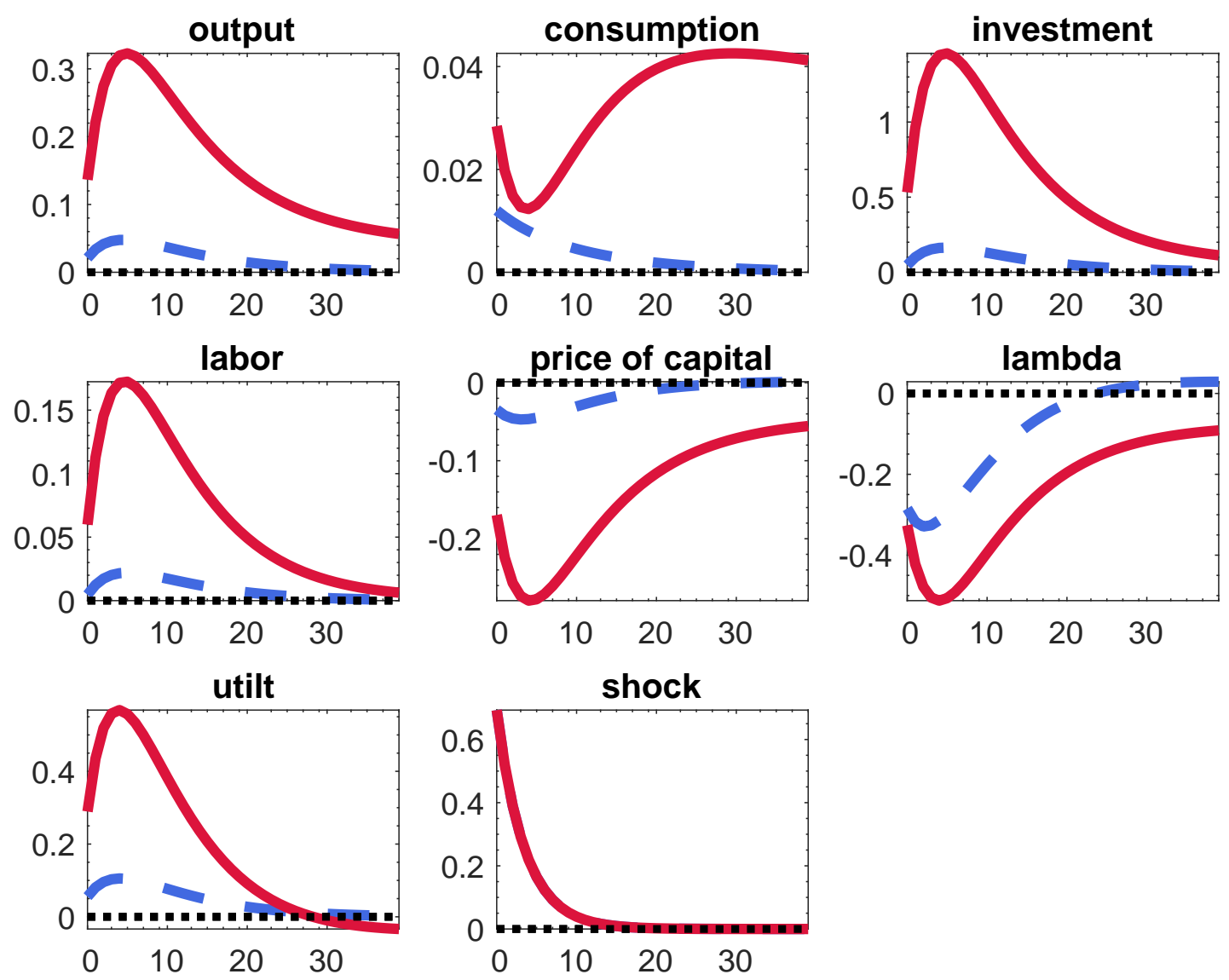

NOTE: Variables correspond to percentage deviations from their steady states.

cle fluctuations than advanced economies can be related, in part, to this interaction between uncertainty shocks and financial frictions. Our prior is that emerging economies are subject both to larger uncertainty shocks and tighter financial frictions.

\section{Conclusion}

In this paper, we have shown how uncertainty shocks can help us understand important aspects of business cycle fluctuations. More concretely, we have investigated how uncertainty shocks interact in a non-trivial way with financial frictions. By complicating future investment in physical capital, tighter financial frictions induce large contemporary reactions to uncertainty shocks.

However, there is much that we can do in this literature. We now outline four avenues of research. First, we can take this class of models to the next level, evaluating the interactions 
of financial frictions and heterogeneity in a context with changing volatility. FernándezVillaverde et al. (2019a) show the rich non-linear dynamics generated by the interaction of financial frictions and heterogeneity and show how they are related to the underlying level of uncertainty in the economy. However, the paper does not explore the role of transitory uncertainty shocks.

Second, uncertainty shocks can also interact with models with a multiplicity of equilibria. An example of this interaction is in Fernández-Villaverde et al. (2019b). In most models analyzed by the literature (including the one in this paper), the effect of uncertainty shocks is transitory. In comparison, Fernández-Villaverde et al. (2019b) show that changes in uncertainty can have considerable effects on the ergodic distributions of aggregate variables. When the economy can fluctuate between two different equilibria, one with high economic activity and low unemployment and one with low economic activity and high unemployment, the level of uncertainty will determine how often we switch between these two equilibria. Fernández-Villaverde et al. (2019b) deliver such results through search complementarities, but there are many other ways to achieve the same outcome. Uncertainty shocks can, therefore, have long-lasting effects.

Third, we need further explorations of the role of the endogeneity of uncertainty shocks. Are business cycles driven by uncertainty shocks, or are uncertainty shocks driven by business cycles, as argued, for example, by Bachmann and Moscarini (2011) and Bachmann et al. (2013)? For example, Van Nieuwerburgh and Veldkamp (2006) have argued that when firms produce less, the flow of new information to other agents in the economy slows down, and uncertainty increases (imagine a situation where production decisions by firms inform other agents about the productivity of a new technology; see Saijo, 2017). Or can we have a situation where we face a mix of the two causality directions? For instance, an uncertainty shock can lower economic activity and, with it, the flow of information.

Fourth, we should study in more depth the interaction between models of endogenous growth and uncertainty shocks. At the core of endogenous growth models, we have technology adoption decisions that depend on valuations of future profits from such adoption. By shifting such a valuation, uncertainty shocks can have permanent effects on the level of output.

We hope to see many more papers coming in this literature during the next decade from young and adventurous researchers. 


\section{References}

Abel, A. (1983): "Optimal Investment under Uncertainty," American Economic Review, 73, 228-33.

Aghion, P. And A. BanerJee (2005): Volatility and Growth, Oxford University Press.

Álvarez, F. And U. J. Jermann (2005): "Using Asset Prices to Measure the Persistence of the Marginal Utility of Wealth," Econometrica, 73, 1977-2016.

Andreasen, M., J. Fernández-Villaverde, and J. Rubio-Ramírez (2018): "The Pruned State-Space System for Non-Linear DSGE Models: Theory and Empirical Applications," Review of Economic Studies, 85, 1-49.

Arellano, C., Y. Bai, And P. J. Kehoe (2019): "Financial Frictions and Fluctuations in Volatility," Journal of Political Economy, 127, 2049-2103.

Aruoba, S. B., J. Fernández-Villaverde, and J. F. Rubio-Ramírez (2006): "Comparing Solution Methods for Dynamic Equilibrium Economies," Journal of Economic Dynamics and Control, 30, 2477-2508.

Bachmann, R., S. Elstner, And E. Sims (2013): "Uncertainty and Economic Activity: Evidence from Business Survey Data," American Economic Journal: Macroeconomics, 5, 217-49.

Bachmann, R. And G. Moscarini (2011): "Business Cycles and Endogenous Uncertainty," 2011 Meeting Papers 36, Society for Economic Dynamics.

Bansal, R. And A. Yaron (2004): "Risks for the Long Run: A Potential Resolution of Asset Pricing Puzzles," Journal of Finance, 59, 1481-1509.

Barillas, F., L. P. Hansen, And T. J. Sargent (2009): "Doubts or Variability?" Journal of Economic Theory, 144, 2388 - 2418.

Barro, R. J. (2006): "Rare Disasters and Asset Markets in the Twentieth Century," Quarterly Journal of Economics, 121, 823-866.

Barro, R. J. AND J. F. URsúa (2008): "Macroeconomic Crises since 1870," Working Paper 13940, National Bureau of Economic Research.

BAsu, S. AND B. Bundick (2017): "Uncertainty Shocks in a Model of Effective Demand," Econometrica, 85, 937-958. 
Bates, D. S. (1996): "Jumps and Stochastic Volatility: Exchange Rate Processes Implicit in Deutsche Mark Options," Review of Financial Studies, 9, 69-107.

Bekaert, G., M. Hoerova, And M. Lo Duca (2013): "Risk, Uncertainty and Monetary Policy," Journal of Monetary Economics, 60, 771-788.

Bernanke, B., M. Gertler, and S. Gilchrist (1999): "The financial accelerator in a quantitative business cycle framework," in Handbook of Macroeconomics, ed. by J. B. Taylor and M. Woodford, Elsevier, vol. 1, Part C, chap. 21, 1341-1393, 1 ed.

Bernanke, B. S. (1983): "Irreversibility, Uncertainty, and Cyclical Investment," Quarterly Journal of Economics, 98, 85-106.

- (2004): "The Great Moderation," Remarks by Governor Ben S. Bernanke, At the meetings of the Eastern Economic Association, Washington, DC, February 20, 2004.

Bianchi, F., C. L. Ilut, And M. Schneider (2017): "Uncertainty Shocks, Asset Supply and Pricing over the Business Cycle," Review of Economic Studies, 85, 810-854.

Blei, D. M., A. Y. NG, And M. I. Jordan (2003): "Latent Dirichlet Allocation," Journal of Machine Learning Research, 3, 993-1022.

Bloom, N. (2009): "The Impact of Uncertainty Shocks," Econometrica, 77, 623-685. (2014): "Fluctuations in Uncertainty," Journal of Economic Perspectives, 28, 153-76.

Bloom, N., S. R. Baker, And S. J. Davis (2016): "Measuring Economic Policy Uncertainty," The Quarterly Journal of Economics, 131, 1593-1636.

Bloom, N., M. Floetotto, N. Jaimovich, I. Saporta-Eksten, and S. J. Terry (2018): "Really Uncertain Business Cycles," Econometrica, 86, 1031-1065.

Bollerslev, T. (1986): "Generalized Autoregressive Conditional Heteroskedasticity," Journal of Econometrics, 31, 307 - 327.

- (2008): "Glossary to ARCH (GARCH)," CREATES Research Papers 2008-49, Department of Economics and Business Economics, Aarhus University.

Bollerslev, T., G. Tauchen, And H. Zhou (2009): "Expected Stock Returns and Variance Risk Premia," Review of Financial Studies, 22, 4463-4492. 
Caldara, D., J. Fernández-Villaverde, J. F. Rubio-Ramírez, and W. Yao (2012): "Computing DSGE Models with Recursive Preferences and Stochastic Volatility," Review of Economic Dynamics, 15, 188 - 206.

Cho, J.-O., T. Cooley, And H. S. Kim (2015): "Business Cycle Uncertainty and Economic Welfare," Review of Economic Dynamics, 18, 185-200.

Cogley, T. and T. Sargent (2005): "Drift and Volatilities: Monetary Policies and Outcomes in the Post WWII U.S," Review of Economic Dynamics, 8, 262-302.

Comín, D. And M. Gertler (2006): "Medium-Term Business Cycles," American Economic Review, 96, 523-551.

Cooley, T. F. (1995): Frontiers of Business Cycle Research, Princeton University Press.

Cooley, T. F. And E. C. Prescott (1995): "Economic Growth and Business Cycles," in Frontiers of Business Cycle Research, ed. by T. F. Cooley, Princeton: Princeton University Press, 1-38.

Cúrdia, V., M. Del Negro, and D. L. Greenwald (2014): "Rare Shocks, Great Recessions," Journal of Applied Econometrics, 29, 1031-1052.

Davis, S. J. And J. A. Kahn (2008): "Interpreting the Great Moderation: Changes in the Volatility of Economic Activity at the Macro and Micro Levels," Journal of Economic Perspectives, 22, 155-180.

Diebold, F. X. (1986): "Modeling the Persistence Of Conditional Variances: A Comment," Econometric Reviews, 5, 51-56.

Dixit, A. AND R. PindyCK (1994): Investment under Uncertainty, Princeton University Press.

Drechsler, I. And A. Yaron (2011): "What's Vol Got to Do with It," Review of Financial Studies, 24, 1-45.

Engle, R. F. (1982): "Autoregressive Conditional Heteroscedasticity with Estimates of the Variance of United Kingdom Inflation," Econometrica, 50, 987-1007.

Epstein, L. G. (1999): "A Definition of Uncertainty Aversion," Review of Economic Studies, 66, 579-608.

Epstein, L. G. And M. Schneider (2007): "Learning Under Ambiguity," Review of Economic Studies, 74, 1275-1303. 
Epstein, L. G. And S. E. Zin (1989): "Substitution, Risk Aversion, and the Temporal Behavior of Consumption and Asset Returns: A Theoretical Framework," Econometrica, 57, 937-969.

Farhi, E. And J. Tirole (2012): "Bubbly Liquidity," Review of Economic Studies, 79, $678-706$.

Fernández-Villaverde, J. (2010): "The Econometrics of DSGE Models," SERIEs: Journal of the Spanish Economic Association, 1, 3-49.

Fernández-Villaverde, J., P. Guerrón-Quintana, K. Kuester, and J. RubioRAmírez (2015a): "Fiscal Volatility Shocks and Economic Activity," American Economic Review, 105, 3352-84.

Fernández-Villaverde, J., P. Guerrón-Quintana, and J. F. Rubio-Ramírez (2015b): "Estimating Dynamic Equilibrium Models with Stochastic Volatility," Journal of Econometrics, 185, 216 - 229.

Fernández-Villaverde, J., P. Guerrón-Quintana, J. F. Rubio-Ramírez, and M. Uribe (2011): "Risk Matters: The Real Effects of Volatility Shocks," American Economic Review, 101, 2530-2561.

Fernández-Villaverde, J., S. Hurtado, and G. Nuño (2019a): "Financial Frictions and the Wealth Distribution," Working Paper 26302, National Bureau of Economic Research.

Fernández-Villaverde, J. And O. Levintal (2018): "Solution Methods for Models with Rare Disasters," Quantitative Economics, 9, 903-944.

Fernández-Villaverde, J., F. Mandelman, Y. Yu, and F. Zanetti (2019b): "Search Complementarities, Aggregate Fluctuations, and Fiscal Policy," Working Paper 26210, National Bureau of Economic Research.

Fernández-Villaverde, J., J. Rubio-Ramírez, and F. Schorfheide (2016): "Chapter 9 - Solution and Estimation Methods for DSGE Models," in Handbook of Macroeconomics, ed. by J. B. Taylor and H. Uhlig, Elsevier, vol. 2, 527 - 724.

Fernández-Villaverde, J. And J. F. Rubio-Ramírez (2013): "Macroeconomics and Volatility: Data, Models, and Estimation," in Advances in Economics and Econometrics: Tenth World Congress, ed. by D. Acemoglu, M. Arellano, and E. Dekel, Cambridge University Press, vol. 3 of Econometric Society Monographs, 137-183. 
Fernández-Villaverde, J. And D. Z. Valencia (2018): "A Practical Guide to Parallelization in Economics," Working Paper 24561, National Bureau of Economic Research.

Gabaix, X. (2011): "Disasterization: A Simple Way to Fix the Asset Pricing Properties of Macroeconomic Models," American Economic Review, 101, 406-09.

(2012): "Variable Rare Disasters: An Exactly Solved Framework for Ten Puzzles in Macro-Finance," Quarterly Journal of Economics, 127, 645-700.

Gilboa, I. And D. Schmeidler (1989): "Maxmin Expected Utility with Non-unique Prior," Journal of Mathematical Economics, 18, 141 - 153.

Gilchrist, S. And J. C. Williams (2000): "Putty-Clay and Investment: A Business Cycle Analysis," Journal of Political Economy, 108, 928-960.

Gourio, F. (2012): "Disaster Risk and Business Cycles," American Economic Review, 102, $2734-2766$.

Guerrón, P. (2009): "Money demand heterogeneity and the great moderation," Journal of Monetary Economics, 56, 255-266.

Guerrón-Quintana, P. A. (2010): "What you match does matter: the effects of data on DSGE estimation," Journal of Applied Econometrics, 25, 774-804.

Guerrón-Quintana, P. A. And R. Jinnai (2019a): "Financial frictions, trends, and the great recession," Quantitative Economics, 10, 735-773.

— (2019b): "On Asset Prices and Liquidity Shocks," Working paper, Boston College.

Hamilton, J. D. (2016): "Macroeconomic Regimes and Regime Shifts," in Handbook of Macroeconomics, ed. by J. B. Taylor and H. Uhlig, Elsevier, vol. 2 of Handbook of Macroeconomics, chap. 3, $163-201$.

Hartman, R. (1972): "The Effects of Price and Cost Uncertainty on Investment," Journal of Economic Theory, 5, 258-266.

Heathcote, J., K. Storesletten, and G. L. Violante (2009): "Quantitative Macroeconomics with Heterogeneous Households," Annual Review of Economics, 1, 319-354.

Ilut, C. L. And M. Schneider (2014): "Ambiguous Business Cycles," American Economic Review, 104, 2368-99. 
Jurado, K., S. C. Ludvigson, And S. NG (2015): "Measuring Uncertainty," American Economic Review, 105, 1177-1216.

Justiniano, A. And G. E. Primiceri (2008): "The Time-Varying Volatility of Macroeconomic Fluctuations," American Economic Review, 98, 604-41.

Kim, C.-J. And C. R. Nelson (1999): "Has the U.S. Economy Become More Stable? A Bayesian Approach Based on a Markov-Switching Model of the Business Cycle," Review of Economics and Statistics, 81, 608-616.

Kiyotaki, N. And J. Moore (1997): "Credit Cycles," Journal of Political Economy, 105, $211-248$.

Knight, F. H. (1921): The Measurement of Durable Goods Prices, Boston: Hart, Schaffner \& Marx.

Koop, G., M. H. Pesaran, And S. Potter (1996): "Impulse Response Analysis in Nonlinear Multivariate Models," Journal of Econometrics, 74, 119-147.

Kydland, F. E. And E. C. Prescott (1982): "Time to Build and Aggregate Fluctuations," Econometrica, 50, 1345-1370.

Larsen, V. (2017): "Components of Uncertainty," Tech. Rep. 5/2017, Norges Bank.

Leland, H. E. (1968): "Saving and Uncertainty: The Precautionary Demand for Saving," Quarterly Journal of Economics, 82, 465-473.

Levintal, O. (2017): "Fifth-order Perturbation Solution to DSGE Models," Journal of Economic Dynamics and Control, 80, $1-16$.

Lubik, T. A. And F. Schorfheide (2004): "Testing for Indeterminacy: An Application to U.S. Monetary Policy," American Economic Review, 94, pp. 190-217.

LuCAS, JR., R. (1985): Models of Business Cycles, Blackwell.

Maccheroni, F., M. Marinacci, And A. Rustichini (2006): "Ambiguity Aversion, Robustness, and the Variational Representation of Preferences," Econometrica, 74, 14471498.

McConnell, M. M. And G. PÉrez-Quirós (2000): "Output Fluctuations in the United States: What Has Changed since the Early 1980's?" American Economic Review, 90, 1464-1476. 
NAKAJima, J. (2012): "Bayesian Analysis of Generalized Autoregressive Conditional Heteroskedasticity and Stochastic Volatility: Modeling Leverage, Jumps and Heavy-Tails for Financial Time Series," Japanese Economic Review, 63, 81-103.

OI, W. Y. (1961): "The Desirability of Price Instability Under Perfect Competition," Econometrica, 29, 58-64.

SAiJo, H. (2017): "The Uncertainty Multiplier and Business Cycles," Journal of Economic Dynamics and Control, 78, 1-25.

Salgado, S., F. Guvenen, And N. Bloom (2019): "Skewed Business Cycles," Working Paper 26565, National Bureau of Economic Research.

SAndmo, A. (1970): "The Effect of Uncertainty on Saving Decisions," Review of Economic Studies, 37, 353-360.

Sargent, T. (1999): The Conquest of American Inflation, Princeton University Press.

Shephard, N. And T. G. Andersen (2009): "Stochastic Volatility: Origins and Overview," in Handbook of Financial Time Series, ed. by T. Mikosch, J.-P. Kreiß, R. A. Davis, and T. G. Andersen, Springer, 233-254.

ShI, S. (2015): "Liquidity, Assets and Business Cycles," Journal of Monetary Economics, $70,116-132$.

Simon, H. A. (1956): "Dynamic Programming Under Uncertainty with a Quadratic Criterion Function," Econometrica, 24, 74-81.

Sims, C. A. And T. Zha (2006): "Were There Regime Switches in U.S. Monetary Policy?" American Economic Review, 96, 54-81.

Stock, J. H. And M. W. Watson (2003): "Has the Business Cycle Changed and Why?" in NBER Macroeconomics Annual 2002, Volume 17, ed. by M. Gertler and K. Rogoff, MIT Press, 159-230.

Strzalecki, T. (2013): "Temporal Resolution of Uncertainty and Recursive Models of Ambiguity Aversion," Econometrica, 81, 1039-1074.

Swanson, E. T. (2012): "Risk Aversion and the Labor Margin in Dynamic Equilibrium Models," American Economic Review, 102, 1663-1691.

Tallarini, JR., T. D. (2000): "Risk-Sensitive Real Business Cycles," Journal of Monetary Economics, 45, 507-532. 
Theil, H. (1957): "A Note on Certainty Equivalence in Dynamic Planning," Econometrica, $25,346-349$.

Van Nieuwerburgh, S. And L. Veldkamp (2006): "Learning asymmetries in real business cycles," Journal of Monetary Economics, 53, 753-772. 